\title{
LA CARA OPUESTA AL RETRIBUCIONISMO PENAL: LA JUSTICIA RESTAURATIVA Y LA ESPECIAL PROTECCIÓN DE LOS MENORES DE EDAD
}

\author{
Marta María Aguilar Cárceles \\ Profesora Contratada Doctora de Derecho Penal y Criminología de la \\ Universidad de Murcia
}

SUMARIO: I. CUESTIONES GENERALES. 1. Delimitación conceptual e interés de la Justicia Restaurativa 1.1. Movimientos y teorías contribuyentes. 1.2. Integración de otras ramas del conocimiento. 2. Aspectos legislativos. 2.1. Encuadre internacional. 2.1. Ámbito nacional. II. ACTUACIÓN SOBRE COLECTIVOS ESPECIALMENTE VULNERABLES: REFERENCIA A LOS MENORES DE EDAD. III. PROGRAMAS DE JUSTICIA RESTAURATIVA. 1. Características generales. 2. Aplicación en el ámbito penal: adecuación y prevención. IV. CONCLUSIONES. BIBLIOGRAFÍA.

RESUMEN: El presente trabajo tiene como objetivo principal el poner de manifiesto cómo la modernización del Derecho Penal lleva consigo la indiscutible consideración de corrientes más humanitarias propias de la Justicia Restaurativa. Como es sabido, la posible cabida de soluciones extrajudiciales o distintas a las vías convencionales ofertadas por la Administración se convierten en un recurso con múltiples ventajas, ya sea la propia agilización del Sistema de Justicia, como la misma consideración de una salida más resocializadora para el infractor. Ahora bien, pese a ello, lo que no debe perderse de vista es que la principal protagonista dentro de estos procedimientos es la víctima, siendo imprescindible garantizar sus derechos a lo largo de todo el proceso para no llegar a desvirtuar la propia esencia de los modelos restaurativos. Para ello, se comienza haciendo una breve conceptualización y un encuadre legislativo, internacional y nacional, de lo que compete a las medidas alternativas de resolución de conflictos, para proseguir con aquellos aspectos que atañen a los menores de edad como sujetos de especial vulnerabilidad. Finalmente, destacan los aspectos más prácticos de la citada temática, esto es, lo relativo a los programas de actuación y medidas de prevención 
de futuros conflictos a través de la aplicación específica de la mediación penal y de la mediación penitenciaria.

Palabras clave: Justicia Restaurativa, Derecho Penal, resolución de conflictos, mediación, menores

Summary: The main aim of this paper is to demonstrate how the modernization of Criminal Law entails the unquestionable consideration of a more humanitarian perspectives proper to the Restorative Justice. As it is known, the search for extrajudicial solutions or alternatives to the conventional ways offered by the Administration becomes a resource with multiple advantages, either the fact of making a Justice System more dynamic, as the consideration of a more re-socializing ways for the offender. Despite that, the aspect that should be always present is that the main protagonist in these procedures is the victim, being essential to guarantee their rights throughout the process in order to not distort the essence of restorative models. For this, this article begins making a brief conceptualization and a legislative framework, both international and national, of all the aspects that define the alternative measures of conflict resolution, to continue with those aspects that concern to minors as subjects of special vulnerability. Finally, it will be stand out the most practical aspects of this topic, that is, what concerns to action programs and measures to prevent future conflicts through the specific application of criminal mediation and prison mediation.

Keywords: Restorative Justice, Criminal Law, conflict resolution, mediation, minors

\section{Cuestiones generales}

La caracterización del Derecho Penal como ultima ratio no lleva necesariamente a su identificación como una rama del Ordenamiento Jurídico orientada a la retribución o "castigo" por el daño causado, sino todo lo contrario, pues si bien es cierta su conceptualización como la rama del Derecho más en enérgica, lo verdaderamente cierto es que las penas privativas de libertad y las medidas de seguridad orientan sus postulados principales hacia la reeducación y reinserción social. Así pues, desde el punto de vista interventivo, y centrando la cuestión en lo que atañe a la prevención especial (aplicada directamente sobre el que delinque o presenta un estado peligroso), si bien la prevención especial negativa estaría orientada al cumplimiento de la sanción o consecuencia jurídica aplicada por el delito cometido, la prevención especial positiva se vincularía ciertamente con unos fines más humanitarios, estos son, el conjunto de herramientas que han de serle dadas al sujeto en aras a evitar su reincidencia, siendo por ello necesario los programas de tratamiento orientados al trabajo de las necesidades criminógenas de tal colectivo. No obstante, habría que decir que en España ha venido predominando 
una normativa penal bastante rígida y atrasada respecto al entorno europeo, acompañada en su evolución de una legislación penitenciaria más modernizada y humanitaria ${ }^{1}$.

Ante dicho contexto, y siendo una problemática generalizada a nivel mundial, empiezan a resurgir ciertas necesidades de cambio y de replanteamiento de la finalidad de las penas y de actuación de la Administración de Justicia. Concretamente, con un afán mucho más garantista y humanitario en busca de respuestas alternativas a los sistemas retributivos vigentes en las prácticas tradicionales, surgen otras formas de comprensión del quehacer institucional ante la existencia de conflictos que vulneran bienes jurídicos. De manera específica, la opción planteada busca como objeto principal el involucrar de manera activa a las partes en conflicto, siendo precisamente éstas las que colaboran en solventarlo mediante la propuesta de opciones viables y atractivas para ambas partes. En este sentido, no cabe duda de que la Justicia Restaurativa guarda dentro de sí el ideal de "Justicia" ${ }^{2}$, buscando un equilibrio entre la resolución alternativa al conflicto (no punitiva) y la cobertura de las necesidades resultantes en la comunidad.

En lo que compete de manera específica al ámbito penal, y siguiendo a autores como Fletcher, podrían diferenciarse dos dimensiones dentro del conflicto generado, por un lado, la que atañe a sujeto activo y sujeto pasivo o, dicho de otro modo, victimario y víctima respectivamente y, de otro lado, la generada entre el Estado y el sospechoso ${ }^{3}$. Conforme a ello, y si bien es cierto que la última de las relaciones ha venido presentándose tradicionalmente, lo cierto es que cada vez toman más fuerza las partes ${ }^{4}$

${ }^{1}$ FERNÁNDEZ BERMEJO, D., "El fin constitucional de la reeducación y reinserción social ¿un derecho fundamental o una orientación política hacia el legislador español?”, Anuario de Derecho Penal y Ciencias Penales (ADPCP), Vol. LXVII, 2014, pp.1 y ss.

2 TAMARIT SUMALLA, J.M., "El necesario impulso de la Justicia restaurativa tras la Directiva europea de 2012", Ars Iuris Salmanticensis, Vol. 1, 2013, pp. 139 y ss.

3 FLETCHER, G., Gramática del derecho penal (Trad. MUÑOZ CONDE, F.), Buenos Aires: Hammurabi, 2008, p.36.

${ }^{4}$ En este sentido baste advertir que, aunque se hable de "partes" en la mayoría del texto, lo cierto es que los sistemas de Justicia Restaurativa siguen unos principios que dejan al margen las vías privadas de resolución de conflictos, principalmente en victimizaciones graves, optando así por otras dinámicas de justicia reparadora que incluyen a la comunidad. Tal es el caso de las conferencias o "dinámicas que permiten desarrollar un diálogo reparador, sin olvidar el vínculo comunitario (...). La característica fundamental de la conferencia es la mayor participación, en comparación con la mediación, de la comunidad local y la comunidad de apoyo de las partes directamente implicadas en el delito", o de los círculos, definidos como una "práctica restaurativa en la cual suelen participar, además de la víctima y el victimario, otras personas afectadas por el delito o interesadas en participar, como los familiares o allegados de ambas, profesionales de la judicatura, de la policía, abogadas y abogados, representantes de la comunidad, etcétera. Todas estas personas se colocan en un círculo, o en varios, y tienen la oportunidad de narrar su vivencia, expresar sus sentimientos, debatir y llegar a acuerdos". En esta línea habría que decir que, mientras los primeros sistemas se han llevado a cabo 
vinculadas por medio del ilícito, permitiendo así una mayor interacción entre ambas. En esta línea, baste señala $r$ que los estudios centrados en la figura de la víctima empiezan a tomar significado a del s.XX ${ }^{5}$, llegando a defender en la actualidad una mayor presencia y protagonismo en el proceso, sea propiamente el proceso penal, como en las medidas alternativas de resolución de conflictivos (MARC), esto es, la Justicia Restaurativa.

En definitiva, puntualizados los extremos anteriores, se procede ahora a analizar la delimitación conceptual y los aspectos legislativos vinculados al ámbito de la Justicia Restaurativa (JR), término empleado en diversos estudios, de manera indiferente, al de "justicia comunitaria", "hacer reparaciones", "justicia positiva”, "justicia relacional”, "justicia reparadora", y "justicia restauradora" ${ }^{6}$, pese a que una visión crítica al respecto pudiera definir dicha identificación como demasiado imprecisa, e incluso, inadecuada.

\section{Delimitación conceptual e interés de la Justicia Restaurativa}

Tomando como referencia la delimitación conceptual de la Oficina de las Naciones Unidas contra la Droga y el Delito (UNODC), la Justicia Restaurativa se define como "una metodología para solucionar problemas que, de varias maneras, involucra a la víctima, al ofensor, a las redes sociales, las instituciones judiciales y la comunidad. Los programas de Justicia Restaurativa se basan en el principio fundamental de que el comportamiento delictivo no solamente viola la ley, sino también hiere a las víctimas y a la comunidad. Cualquier esfuerzo para solucionar las consecuencias del comportamiento delictivo deberá, en la medida de lo posible, involucrar tanto al ofensor como a las partes ofendidas, y proporcionar la ayuda y el apoyo que la víctima y el delincuente requieren", en otras palabras, un proceso restaurativo vendría a ser "cualquier proceso en el que la víctima y el ofensor y, cuando sea adecuado, cualquier otro individuo o miembro de la comunidad afectado por un delito participan en conjunto de manera activa para la resolución de los asuntos

en países como Reino Unido, Canadá, Estados Unidos, Nueva Zelanda o Australia, las segundas dinámicas han sido más propias de países como Alemania, Hungría, Bélgica o Brasil. Vid. más información en: CHOYÁ FORES, N., "Prácticas restaurativas: círculos y conferencias", Justicia restaurativa: nuevas perspectivas en mediación, 2014-2015, pp. 9 y ss. Vid.: http://www.pensamientopenal.com.ar/system/files/2015/07/doctrina41593.pdf

5 Por ejemplo, de la mano de autores como Von Henting y Mendelsohn.

6 MIERS, D., An International Review of Restorative Justice. Crime Reduction Research Series Paper 10, Barry Webb Home Office Policing and Reducing Crime Unit, London, 2001, p. 88. 
derivados del delito, generalmente con la ayuda de un facilitador" 7 . Ante dichas afirmaciones efectuadas por la UNODC, se puede apreciar cómo se niega la reducción de la resolución del conflicto de manera específica a las personas que quedarían implicadas de una forma más directa (víctima y victimario), entendiendo la necesidad de implicación de la propia comunidad a la hora de considerar los posibles efectos de las soluciones a tomar.

Los principios de la Justicia Restaurativa lindan directamente con los Derechos Humanos (DDHH), donde la libertad individual vendría a considerarse como uno de los derechos más fundamentales y de reconocimiento mundial, siendo su privación exclusivamente restringida debido a la legislación penal vigente y por causas tasadas y motivadas pues, en otro orden de cosas, no cabría justificar su aplicación. Conforme a ello, se desarrollan a continuación las características esenciales que atañen a la Justicia Restaurativa pues, ¿acaso no sería la solución a muchos de los problemas con los que se encuentran las instituciones penitenciarias en la actualidad (p.ej., el hacinamiento carcelario)?

\subsection{Movimientos y teorías contribuyentes}

De acuerdo con los postulados de Zehr en el año 1990, "el crimen es una violación que se produce sobre las personas y sobre las relaciones sociales, donde la Justicia implicaría a la víctima, al delincuente y a la comunidad, en una búsqueda de soluciones orientadas a promover la reparación, la reconciliación y la seguridad" ${ }^{8}$, destacando en este caso su similitud con la definición previamente expuesta de la UNODC en relación, precisamente, con los postulados de la Justicia Restaurativa.

Según indican Van Ness y Strong, la tercera vía ("Justicia Restaurativa"), vendría determinada no solo por un movimiento de resolución de litigios informal por parte de los profesionales del ámbito de Justicia que pretendían devolver a los sujetos sus problemas para que fueran capaces de solventarlos, sino también por nuevos movimientos ideológicos que contribuyeron al desarrollo y comprensión de la Justicia Restaurativa entendiendo la restitución como modo preferente a la sanción tradicional del delincuente ${ }^{9}$. A todo ello se suma la demanda de la disciplina victimológica, y no solo lo hace en reclamo de los servicios de restitución económica o financiera, sino en base a la necesidad de una mayor

7 OFICINA DE LAS NACIONES UNIDAS CONTRA LA DROGA Y EL DELITO (UNODC), Manual sobre programas de Justicia Restaurativa. Serie de Manuales sobre Justicia Penal, Viena, 2006, p.6.

8 ZEHR, H., Changing lenses: a new focus for criminal justice, Scottsdale, PA: Herald Press, 1990, p.181.

9 VAN NESS, D. and STRONG, K.H., Restoring justice, Concinnati, OH: Anderson Publishing Co, 1977, p. 18. 
participación en el proceso. De la misma forma, los autores señalan la relevancia de dos circunstancias más que favorecerían la instauración de la Justicia Restaurativa, estas son:

- Los programas de reconciliación-mediación entre víctima y delincuente o pareja-penal, donde quedarían incluidas no solo formas de restitución del daño sino también de reconciliación ente las partes, garantizando así mayores niveles de satisfacción para los intervinientes. Igualmente, destacan los autores la posibilidad de implicar a terceras personas dentro del proceso, como serían los familiares, otras personas de apoyo, o representantes de la comunidad. Esto último es lo que ellos denominan como "family group conferences" 10 .

- La "Justicia Social", definida por los autores como aquel movimiento feminista y abolicionista que enfatiza la injusticia estructural inherente al sistema de Justicia Penal y Penitenciario -en particular hacia los internos-, demandando con ello el desarrollo de respuestas alternativas al delito y una mayor comprensión del Sistema de Justicia ${ }^{11}$.

Siguiendo a Marshall, la Justicia Restaurativa sería tanto una corriente teórica focalizada en determinados valores y principios, como aquel proceso encargado de su implementación, donde los implicados toman parte para resolver colectivamente cómo tratar las consecuencias del ilícito y sus implicaciones futuras ${ }^{12}$. Igualmente, cabría destacar algunas de las teorías que han contribuido a su desarrollo y conceptualización, a saber:

a) "Reintegrative shaming theory", o teoría mediante la cual Braithwaite en el año 1989 y 2002 explicaría la integración social del delincuente a partir de los sentimientos generados tras la realización del delito, concretamente en relación con la "vergüenza" desprendida de la realización de la acción ilícita. De este modo, refiere que los principales fundamentos de estas teorías serían: a1) la tolerancia al delito empeora la situación, a2) la estigmatización del delito hace que el mismo se perciba como peor, y a3) la

10 Dentro de este ámbito, especialmente en lo que compete a los programas de reconciliación entre víctima y delincuente, habría que hacer especial referencia al experimento Kitchener (Canadá), siendo una de las primeras aproximaciones a la incorporación de la mediación dentro de este ámbito. Vid. más información en: PEACHEY, D., "The Kitchener experiment", en M. Wright and B. Galaway (Eds.), Mediation and Criminal Justice; victims, offenders and community, London, Sage, 1989, y MC COLD, P., "La reciente justifica restaurativa. Mediación, círculos y conferencias", Delito y Sociedad 35 (22), $2^{\circ}$ semestre 2013, pp.9-44.

11 Ibidem, pp.19 y ss.

12 MARSHALL, T., Restorative justice: an overview, technical report. London: Home Office, 1999, p.5. 
vergüenza o conciencia sobre el daño y perjuicio ocasionado previene el delito ${ }^{13}$. Igualmente, refiere que la aplicación de la Justicia Restaurativa sería más efectiva en la reducción del crimen.

b) La teoría sobre el procedimiento de justicia de Tyler, en la cual explica que el delincuente que percibe su castigo como justo tiene menos posibilidades de delinquir. Además, indica el autor que las partes suelen percibir la Justicia Restaurativa como más justa que el procedimiento penal ordinario, pues en aquel caso serían ellas mismas las que colaborarían y soportarían las decisiones adoptadas ${ }^{14}$.

Así pues, como indica Gal, una teoría basada en la Justicia Restaurativa incluiría los elementos ya mencionados del siguiente modo: i) promoviendo la participación individual y orientando a los profesionales en la toma de decisiones, ii) enfatizando la relevancia de la reparación hacia la víctima, iii) trabajando los deseos y necesidades de las víctimas como prioridad central, y iv) favoreciendo la aplicación de medidas alternativas a las perspectivas punitivistas ${ }^{15}$.

En definitiva, autores como Morris y Maxwell indican un conjunto de valores sobre los que podría establecerse la Justicia Restaurativa, esto son: i) la primacía del cuidado de las víctimas, de los delincuentes y de la comunidad a través de su inclusión en los procesos de toma de decisiones centradas en cómo tratar o manejar el delito y sus consecuencias, ii) un incremento de la comprensión de las partes implicadas en el proceso, teniendo en consideración las posibles razones que llevaron a realizar el delito y el impacto producido sobre terceros, iii) el respeto por cada una de las partes intervinientes en el proceso, así como la evitación de los procesos de estigmatización o etiquetado social sobre las mismas, iv) la responsabilidad por del delito cometido a través de la compensación, v) la reducción de la reincidencia, vi) la reintegración del delincuente y víctima dentro de la comunidad, y vii) reparación del daño en cuanto al hecho de "curar las heridas" presentes en las víctimas ${ }^{16}$.

13 Vid. Más información en: BRAITHWAITE, J., Crime, shame and reintegration, Cambridge: Cambridge University Press, 1989, y BRAITHWAITE, J., Restorative justice and responsive regulation, New York: Oxford University Press, 2002, p.74.

14 TYLER, T.R., Why people obey the law, New Haven, CT: Yale University Press, 1990.

15 GAL, T., Child victims and restorative justice, Oxford: Oxford University Press, 2011, p.11.

${ }_{16}$ MORRIS, A. \& MAXWELL, G., "Implementing restorative justice: What Works?”, in J. Hudson, A. Morris, G. Maxwell, and B. Galaway (Eds.), Restorative justice for juveniles: conferencing, mediation and circles, Portland, OR: Hart Publishing, 2001, pp. 267-268. 
En cualquiera de los casos, los aspectos a tener en cuenta en la aplicación de los citados programas responden a las siguientes característi$\operatorname{cas}^{17}$ :

a) La existencia de una respuesta flexible e individual a las circunstancias del delito, delincuente y víctima.

b) La reparación de víctimas, delincuentes, y comunidad, bajo un prisma de respeto a la dignidad e igualdad.

c) La aplicación de alternativas al Sistema de Justicia Penal que sean viables y factibles, evitando la estigmatización o etiquetamiento del sujeto activo.

d) El método se caracteriza por poder llevarse a cabo junto con los procesos penales, por estar orientado a solventar el origen de la problemática, cubrir las necesidades de las víctimas, y hacer que el delincuente tenga conciencia del daño generado y asuma su responsabilidad sobre los hechos y consecuencias ocasionadas a terceros, incluyendo aquí tipologías delictivas muy variadas.

e) La respuesta al delito no pasa inadvertida al fomento de la enseñanza de valores prosociales a los responsables, destacando el papel de la comunidad como principal actor de cara a la prevención del delito. En este caso, los medios de control social de tipo informal serían los agentes clave para asegurar el proceso de reinserción y no reincidencia (p.ej., familia, amigos, maestros, vecindario, etc.)

Unido a lo anterior, recuerda también la Oficina de Naciones Unidas cuáles serían las premisas esenciales la que se sustentan los programas de Justicia Restaurativa, a saber ${ }^{18}$ :

- La respuesta al delito debe reparar en la medida de lo posible el daño sufrido por la víctima.

- Los delincuentes deben llegar a entender que su comportamiento no es aceptable y que tiene consecuencias reales para la víctima y la comunidad.

- Los delincuentes pueden y deben aceptar la responsabilidad por sus acciones, ésta sería la única manera de verificar el cambio siempre y cuando dicha conciencia de lo sucedido, y asunción de

17 OFICINA DE LAS NACIONES UNIDAS CONTRA LA DROGA Y EL DELITO (UNODC), Manual sobre programas de Justicia Restaurativa. Serie de Manuales sobre Justicia Penal, Viena, 2014, pp.7 y 8.

18 OFICINA DE LAS NACIONES UNIDAS CONTRA LA DROGA Y EL DELITO (UNODC), Manual sobre programas de Justicia Restaurativa. Serie de Manuales sobre Justicia Penal, Viena, 2010, p. 8. 
la responsabilidad, se real, y no simplemente para evitar consecuencias más severas por la acción cometida.

- Las victimas deben tener la oportunidad de expresar sus necesidades y de participar en determinar la mejor manera para que el delincuente repare los daños, esto es, se tendrá tendida en cuenta la víctima a la hora de buscar soluciones factibles de cara a la solución de conflicto.

- La comunidad tiene la responsabilidad de contribuir en el proceso.

En base a lo anterior, pero de manera específica en lo que atañe a la reparación victimal, autores como Blanco, Díaz, Heskia y Rojas aluden a los siguientes principios básicos, a saber ${ }^{19}$ :

i. Encuentro: Relativo a la creación de espacios de conversación y reunión entre las partes, es decir, entre víctima y victimario. Se trata de un espacio en el que, además, podrán también participar otras personas, y mediante el cual se pretende facilitar un mayor compromiso por parte de los intervinientes, así como la consecución de acuerdos satisfactorios.

ii. Reparación: Centrada especialmente en la víctima directa del delito, pero sin dejar al margen otros agentes perjudicados (p.j., víctimas indirectas), este principio se fundamenta en la necesidad de adoptar medidas que atiendan los daños ocasionados (p.ej., reparación, reconciliación, compensación pecuniaria, etc.).

iii. Reintegración: Se trata de un concepto que comulga totalmente con las premisas constitucionales de la reeducación y reinserción social, en aras a evitar la reiteración o reincidencia futura de los sujetos activos del delito o de sus potenciadores. En este sentido, a la vez que se promueve la asunción de responsabilidad por parte del autor de la acción sancionada, también evita la facilitación de la estigmatización social propia hacia la figura del delincuente.

iv. Inclusión: Relativa a la colaboración y participación activa de las partes en las distintas etapas, siempre bajo el prisma de la voluntariedad en la implicación de proceso.

En definitiva, y dicho todo lo anterior, no cabe duda de que el elemento esencial de la Justicia Restaurativa es el de reparar, tanto como sea posible, el daño causado a la víctima ${ }^{20}$, siendo su esencia no tanto la

19 BLANCO, R., DÍAZ, A., HESKIA, J y ROJAS, H., Justicia Restaurativa: Marco Teórico, Experiencias Comparadas y Propuestas de Política Pública, Universidad Alberto Hurtado, Colecciones de Investigaciones Jurídicas 6, 2014, pp. 10 y ss.

20 WALGRAVE, L., "Restorative justice and human rights", in T. Gavrielides (Ed.), Rights and restoration within youth justice, Sitter Publications: Canada, 2012, p.1225. 
finalidad perseguida como el significado de las soluciones conseguidas ${ }^{21}$. Pese a ello, si bien es cierto que hasta el momento pudiera parecer que, aparentemente el más beneficiado viene a ser precisamente la persona que realiza la infracción, lo cierto es que dicha percepción no puede ser una realidad, pues entonces las expectativas de la propia víctima en el Sistema de Justica podrían quedar anuladas. En este sentido, resulta fundamental su participación, que sea ella misma la que también aporte las posibles soluciones y que éstas sean debatidas por las partes, que note el apoyo de la comunidad a diferentes niveles y, sobre todo, evitar que dicho proceso alternativo llegue a generar una victimización secundaria, pues la revictimización supondría una desconfianza absoluta de la víctima en el sistema.

\subsection{Integración de otras ramas del conocimiento}

La relación entre el Derecho Penal, la Psicología, la Criminología, y la Victimología — como disciplina científica dentro de esta última-, se hace evidente si se tiene en consideración las secuelas psicológicas y emocionales generadas en la víctima tras el desarrollo de un trauma, trauma entendido en términos generales como las consecuencias desprendidas de un hecho antisocial y/o ilícito, en definitiva, cualquier hecho traumático. En este sentido, podría incluso llegar a afirmarse que el groso de la investigación llevada a cabo sobre las experiencias victimales se ha establecido sobre las consecuencias psicológicas derivadas de los procesos de victimización.

De sobra son conocidas las interrelaciones existentes entre la Psicología y la Justicia Restaurativa, pudiendo admitir que los primeros autores que escribieron y desarrollaron estudios en dicho campo eran psicólogos sociales, clínicos y $\operatorname{cognitivos}^{22}$; es más, la Psicología siempre se ha situado en un plano muy cercano al de la Criminología (p.ej. a nivel forense, perfilación criminal, tratamiento a delincuentes, programas de prevención del delito y de apoyo a las víctimas, comportamiento desviado, instituciones juveniles, bullying, etc.). en esta línea, se presenta seguidamente una tabla resumen relativa a las relaciones o vínculos que existen, entre otros, a través de la Psicología y la Justicia Restaurativa, a saber:

${ }^{21}$ MC COLD, P., Paradigm muddle: The threat to restorative justice posed by its merger with community justice, Contemporary Justice Review 7(1), 2004, p.15.

${ }^{22}$ ARTINOPOULOU, V., "Restorative justice and Psychology: positivism in Criminology again?", in T. Gavrielides (Ed.), The Psychology of restorative justice: Managing the power within, Ashgate, Surrey (England), 2015, p.87. 
Tabla 1. Aspectos comunes objeto de estudio entre la Psicología y la Justicia Restaurativa ${ }^{23}$.

\begin{tabular}{|c|c|}
\hline A nivel teórico & Prácticas/nivel político \\
\hline $\begin{array}{c}\text { Individual, comunitario, crimen } \\
\text { como violación de los límites de las } \\
\text { relaciones interpersonales y sociales, } \\
\text { responsabilidad, empatía, etc. }\end{array}$ & Mediación, terapia, etc. \\
\hline Investigación empírica & Campo de implementación \\
\hline $\begin{array}{c}\text { Metodología cuantitativa (p.ej. entre- } \\
\text { vista, estudio de caso, sesiones grupa- } \\
\text { les, etc.) }\end{array}$ & $\begin{array}{c}\text { Sistema de Justicia Penal, comu- } \\
\text { nidad, escuela, lugares de trabajo, } \\
\text { prisiones, etc. }\end{array}$ \\
\hline
\end{tabular}

\section{Aspectos legislativos}

Las prácticas en Justicia Restaurativa han ido creciendo gradual y significativamente durante los últimos 20 años en Europa, donde cada vez un mayor número de víctimas y delincuentes se han visto envueltos en este tipo de medidas alternativas de resolución de conflictos, principalmente en los procesos de mediación ${ }^{24}$. En este sentido, y dada su relevancia, se procede a continuación a realizar una síntesis de la principal normativa promotora de dicha corriente tanto a nivel nacional como internacional, dando comienzo a partir de esta última.

\subsection{Encuadre internacional}

La base de los movimientos propios de la Justicia Restaurativa como forma más humanitaria de comprender, no solo la solvencia de los conflictos o litigios, sino en propio Derecho Penal, nace con fuerza a mediados de s.XX. Así, frente a las corrientes más retributivas propia de dicha rama del Ordenamiento Jurídico, nace en el año 1955 de la mano de Naciones Unidas lo que podría definirse como el Primer Congreso celebrado en esta materia, lo que supone un reclamo social evidente sustentado en una demanda ciudadana que se apoya en una visión o pensamiento más solidario y compasivo. En este sentido, dicho Congreso, cuya celebración fue en Ginebra, viene a asentar las Reglas Mínimas para el Tratamiento

${ }^{23}$ Ibídem, pp.87 y ss.

${ }^{24}$ LAUWAER, K., "European criminal justice policies on victims and restorative justice”, in I. Vanfraechem, D. Bolívar and I. Aertsen (Eds.), Victims and restorative justice, Oxfordshire, Routledge, 2015, p.239. 
de los Reclusos, dando paso así a la expansión de la Justicia Restaurativa en materia de prevención del delito y de Justicia penal, la cual viene a afectar directamente a la propia Administración Penitenciaria ${ }^{25}$.

En este sentido, habiendo destacado el primero de ellos, una representación cronológica de los congresos quinquenales que, por parte de $\mathrm{Na}$ ciones Unidas, han venido tanto a fortalecer la cooperación internacional contra la expansión de la delincuencia como a repercutir, de manera considerable, en las políticas públicas de Justicia Penal y en la necesidad de una mayor cooperación y colaboración internacional, sería la siguiente ${ }^{26}$ :

\section{Tabla 2. Descripción cronológica de los distintos Congresos de Naciones Unidas en materia de prevención del delito y Justicia Penal ${ }^{27}$.}

\begin{tabular}{|c|c|c|}
\hline Año & $\begin{array}{c}\text { Lugar de } \\
\text { celebración }\end{array}$ & Denominación y descripción del Congreso \\
\hline 1955 & $\begin{array}{l}\text { Ginebra } \\
\text { (Suiza) }\end{array}$ & $\begin{array}{l}\text { Primer Congreso. Aprobación de las Reglas mínimas } \\
\text { para el tratamiento de los reclusos. }\end{array}$ \\
\hline 1960 & $\begin{array}{l}\text { Londres } \\
\text { (Reino } \\
\text { Unido) }\end{array}$ & $\begin{array}{l}\text { Segundo Congreso. Recomendación de servicios especia- } \\
\text { les de policía para la justicia de menores. }\end{array}$ \\
\hline 1965 & $\begin{array}{c}\text { Estocolmo } \\
\text { (Suecia) }\end{array}$ & $\begin{array}{l}\text { Tercer Congreso. Análisis de la relación entre la delin- } \\
\text { cuencia y la evolución social. }\end{array}$ \\
\hline 1970 & $\begin{array}{l}\text { Kyoto } \\
\text { (Japón) }\end{array}$ & $\begin{array}{l}\text { Cuarto Congreso. Se aconseja e insiste sobre la plani- } \\
\text { ficación de la prevención del delito para el desarrollo } \\
\text { económico y social. }\end{array}$ \\
\hline 1975 & $\begin{array}{l}\text { Ginebra } \\
\text { (Suiza) }\end{array}$ & $\begin{array}{l}\text { Quinto Congreso. Aprobación de la Declaración sobre } \\
\text { la Protección de Todas las Personas contra la Tortura y } \\
\text { Otros Tratos o Penas Crueles, Inhumanos o Degradantes. }\end{array}$ \\
\hline 1980 & $\begin{array}{c}\text { Caracas } \\
\text { (Venezuela) }\end{array}$ & $\begin{array}{l}\text { Sexto Congreso. Reconocimiento de las bases de la } \\
\text { prevención del delito en las circunstancias sociales, cul- } \\
\text { turales, políticas y económicas de los países. (Tema "La } \\
\text { prevención del delito y la calidad de la vida"). }\end{array}$ \\
\hline
\end{tabular}

25 Ver más información en: Primer Congreso de las Naciones Unidas sobre la Prevención del Delito y Tratamiento del Delincuente. Ginebra, del 22 de agosto al 3 de septiembre de 1955.

${ }^{26}$ Información disponible en: NACIONES UNIDAS (NACIONES UNIDAS), Congresos de las Naciones Unidas sobre prevención del delito y justicia penal 1955 - 2015. 60 años de logros, United Nations Information Service, 2015. Disponible en: https://www.un.org/es/ events/crimecongress2015/pdf/60_years_booklet_ES.pdf

27 Elaboración propia a partir de ibídem. 


\begin{tabular}{|c|c|c|}
\hline Año & $\begin{array}{l}\text { Lugar de } \\
\text { celebración }\end{array}$ & Denominación y descripción del Congreso \\
\hline 1985 & $\begin{array}{l}\text { Milán } \\
\text { (Italia) }\end{array}$ & $\begin{array}{l}\text { Séptimo Congreso. Aprobación del Plan de Acción de } \\
\text { Milán y varias reglas y normas nuevas de las Naciones } \\
\text { Unidas. (Tema: "Prevención del delito para la libertad, la } \\
\text { justicia, la paz y el desarrollo"). }\end{array}$ \\
\hline 1990 & $\begin{array}{l}\text { La Habana } \\
(\text { Cuba) }\end{array}$ & $\begin{array}{l}\text { Octavo Congreso. Recomendación sobre la necesidad de } \\
\text { adopción de medidas contra la delincuencia organizada } \\
\text { y el terrorismo. (Tema: "La cooperación internacional } \\
\text { en materia de prevención del delito y justicia penal en el } \\
\text { siglo XXI"). }\end{array}$ \\
\hline 1995 & $\begin{array}{l}\text { El Cairo } \\
\text { (Egipto) }\end{array}$ & $\begin{array}{l}\text { Noveno Congreso. Cooperación internacional y asistencia } \\
\text { técnica de carácter práctico para fortalecer el estado de } \\
\text { derecho. (Tema: "Menos crimen, más justicia: seguridad } \\
\text { para todos"). }\end{array}$ \\
\hline 2000 & $\begin{array}{c}\text { Viena } \\
\text { (Austria) }\end{array}$ & $\begin{array}{l}\text { Décimo Congreso. Aprobación de la Declaración de Viena } \\
\text { en la que los Estados Miembros se comprometieron for- } \\
\text { talecer la cooperación internacional en la lucha contra la } \\
\text { delincuencia transnacional y la reforma penal. }\end{array}$ \\
\hline 2005 & $\begin{array}{l}\text { Bangkok } \\
\text { (Tailandia) }\end{array}$ & $\begin{array}{l}\text { Onceavo Congreso. Aprobación de la Declaración de } \\
\text { Bangkok, un documento político crucial en el que se } \\
\text { establecen los fundamentos de la coordinación y cooper- } \\
\text { ación internacionales con miras a prevenir y combatir la } \\
\text { delincuencia y se imparten directrices para fortalecer esa } \\
\text { coordinación y cooperación. }\end{array}$ \\
\hline 2010 & $\begin{array}{l}\text { El Salvador } \\
\text { (Brasil) }\end{array}$ & $\begin{array}{l}\text { Doceavo Congreso. Destaca el papel fundamental del } \\
\text { Sistema de Justicia Penal en el desarrollo un enfoque } \\
\text { holístico respecto de la reforma del sistema judicial con } \\
\text { objeto de reforzar la capacidad de los sistemas de justicia } \\
\text { penal en la lucha contra el delito, y determinó medios de } \\
\text { prevenir y controlar las nuevas formas de delincuencia en } \\
\text { todo el mundo. }\end{array}$ \\
\hline 2015 & $\begin{array}{l}\text { Doha } \\
\text { (Catar) }\end{array}$ & $\begin{array}{l}\text { Treceavo Congreso. Examen de la integración de la pre- } \\
\text { vención del delito y la justicia penal en la agenda más } \\
\text { amplia de las Naciones Unidas. }\end{array}$ \\
\hline 2020 & $\begin{array}{l}\text { Kyoto } \\
\text { (Japón) }\end{array}$ & $\begin{array}{l}\text { Catorceavo Congreso sobre Prevención del Delito y Jus- } \\
\text { ticia Penal. }\end{array}$ \\
\hline
\end{tabular}

Conforme a todo lo anterior, baste mencionar brevemente algunos de los hitos más destacados en materia de Justicia Restaurativa; concreta- 
mente, y haciendo mención a los Congresos más actuales de los mencionados con anterioridad, baste destacar los siguientes, a saber:

a) La Declaración de Viena sobre la Delincuencia y la Justicia: Frente a los Retos del Siglo Veintiuno (2000) favoreció el "desarrollo de políticas, procedimientos y programas de Justicia Restaurativa que sean respetuosos a los derechos, necesidades e intereses de las víctimas, los delincuentes, las comunidades y todas las demás partes" 28 .

b) La Declaración de Bangkok- Sinergias y respuestas: Alianzas Estratégicas sobre Prevención del Delito y Justicia penal o declaración del Decimoprimer Congreso de las Naciones Unidas sobre la Prevención del Delito y el Trato de Delincuentes (2005), en la cual se instaba a los diversos Estados Miembros al desarrollo de políticas, procedimientos y programas de Justicia Restaurativa que incluyesen alternativas a los procesos judiciales ${ }^{29}$.

c) La Declaración de Salvador abre la puerta a todas aquellas problemáticas vinculadas con la cibercriminalidad o delincuencia cibernética (2010), lo que trae consigo multitud de respuestas desde el ámbito tanto nacional como internacional. Además, entre los temas objeto de debate destacan aquellos que tienen por objeto la población infanto-juvenil y su vinculación con la criminalidad, así como el tráfico de migrantes, terrorismo y el lavado de dinero, entre otros ${ }^{30}$. En esta línea, baste destacar cómo los actos delictivos vinculados con el blanqueo de capitales y lavado de dinero se han visto potenciados por el desarrollo de las nuevas tecnologías, de ello su necesidad de cobertura a nivel legislativo.

d) La Declaración de Doha sobre la integración del delito y la Justicia Penal en el marco más amplio del programa de Naciones Unidas para abordar los problemas sociales y económicos y promover el Estado de Derecho a nivel nacional e internacional y la participación pública (2015), en la cual se indica expresamente la necesidad de "apoyar unos sistemas de justicia penal eficaces, imparciales, humanos y responsables", a lo que añade la importancia de alentar

28 Declaración de Viena sobre delito y Justicia: Enfrentando los Retos del Siglo Veintiuno, 10. Congreso de las Naciones Unidas s obre la Prevención del Delito y el Tratamiento a Delincuentes, Viena, 10-17 de Abril 2000, A/CONF. 184/4/Rev. 3, párrafo 29.

29 Declaración de Bangkok- Sinergias y respuestas: Alianzas Estratégicas sobre Prevención del Delito y Justicia Penal, 11vo. Congreso de las Naciones Unidas sobre la Prevención del Delito y el Trato a Delincuentes, Bangkok, 18-25 de Abril del 2005, párrafo 32.

30 Declaración de Salvador abre la puerta a todas aquellas problemáticas vinculadas con la cibercriminalidad o delincuencia cibernética (2010). Disponible en: https://www. unodc.org/documents/crime-congress/12th-Crime-Congress/Documents/Salvador_ Declaration/Salvador_Declaration_S.pdf 
una "participación efectiva (...), lo cual permitirá crear las condiciones necesarias para promover el programa más amplio de las Naciones Unidas" ${ }^{31}$.

Por último, baste cerrar el listado anterior con la mención al Catorceavo Congreso de Naciones Unidas cuyo eje sustantivo, como la misma Oficina lo define, viene a asentarse sobre la "Promoción de la prevención del delito, la justicia penal y el estado de derecho: hacia el cumplimiento de la Agenda 2030". Si bien en 2020 repite nuevamente Kyoto como sede de celebración y acogida, los debates que en esta ocasión se llevarán a cabo versarán sobre temas bien distintos a los ya mencionados en Japón hace cincuenta años. De manera específica, los factores de riesgo vienen a ser un punto esencial de cara a la prevención de la reincidencia, así como la importancia concedida a las nuevas tecnologías en la perpetración de los tipos penales, principalmente en su empleo como medio o herramienta de comisión de ilícitos; de la misma forma, destaca expresamente el papel de los más jóvenes en relación a dos aspectos de vital importancia: a) su consideración dentro del ámbito educativo y, por tanto, en la comprensión de dicho sistema como medio de control social informal del delito, y b) en la necesidad de su participación activa en la prevención de la criminalidad, potenciando lo que vienen a denominar como "sociedades resilientes". En esta línea, destaca la relevancia concedida a la resiliencia, no solo desde el punto de vista individual, sino que al margen del plano personal la promoción de mecanismos o herramientas que permitan a una sociedad determinados hechos traumáticos, como sería el caso de la vivencia de hechos delictivos (p.ej., actos terroristas), se incluye como premisa básica dentro de la propia convivencia social.

Pero pese a los Congresos mencionados previamente, no cabe pasar inadvertidas las Decisiones o Resoluciones que, efectuadas desde el ámbito internacional, han tenido un papel crucial en el desarrollo de la Justicia Restaurativa en los últimos años. En este sentido, podrían resaltarse las siguientes:

- Adopción de la Decisión del año 2001 en la que se declara que los Estados deberán promover la mediación en casos criminales e implementar instrumentos legales para ello para el año $2006^{32}$.

- El listado de Principios Básicos sobre la utilización de programas de Justicia Restaurativa en Materia penal (2002), el cual fue adop-

31 Informe sobre la Declaración de Doha sobre la integración del delito y la Justicia Penal en el marco más amplio del programa de NACIONES UNIDAS para abordar los problemas sociales y económicos y promover el Estado de Derecho a nivel nacional e internacional y la participación pública (2015). Material disponible en: https://www. unodc.org/documents/congress/Declaration/V1504154_Spanish.pdf

32 Decisión de Trabajo del Consejo de la Unión Europea del 15 de Marzo de 2001 sobre la Postura de las Víctimas en Procedimientos Penales, Artículo 10. 
tado por resolución del Consejo Económico y Social de las Naciones Unidas convocando así a su uso a aquellos Estados Miembro que estaban implementando aquel tipo de programas ${ }^{33}$.

- Resolución aprobada por el Consejo Económico y Social el 26 de julio de 2016, por recomendación de la Comisión de Prevención del Delito y Justicia Penal (E/2016/30), la cual alude nuevamente al ámbito de la Justicia Restaurativa en asuntos penales ${ }^{34}$.

De todo lo anterior, y a efectos de una mayor comprensión de las políticas que empiezan a incidir a partir del s.XXI, cabe destacar el propio listado de valores de proceso de Justicia Restaurativa que encuadra Naciones Unidas en su Manual del año $2006^{35}$, a saber: i) participación y fortalecimiento de los intervinientes, ii) respeto por todos los participantes, iii) previsión de resultados, no impuestos, iv) compromiso de las partes con el acuerdo logrado a lo largo del proceso, v) flexibilidad y respuesta del proceso y los resultados, y vi) fortalecimiento de la comunidad. Por su parte, desde el ámbito europeo, cabría destacar la Directiva 2012/29/UE del Parlamento Europeo y de Consejo, de 25 de octubre de 2012, por la que se establecen normas mínimas sobre los derechos, el apoyo y la protección de las víctimas de delitos, y por la que se sustituye la Decisión marco 2001/220/JAI del Consejo ${ }^{36}$. En la misma línea, no solo se detalla la conceptualización de víctima, sino que además se alude a la necesidad de una intervención personalizada, obligando a los Estados Miembros a asegurar que las víctimas son reconocidas y tratadas con respeto y que sus necesidades son cubiertas desde una perspectiva individualizadora, teniendo acceso igualmente a todos los sistemas de apoyo disponibles.

$\mathrm{Al}$ margen de lo anterior, pero siguiendo con la mencionada Directiva de 2012, cabría destacar la definición ofrecida sobre el concepto "Justicia Restaurativa”, indicando en su Artículo 2.1(d) que se considerará como tal "cualquier proceso en el que la víctima o el delincuente sean capaces, si libremente lo consienten, en participar activamente en la resolución de conflictos que atañen al ámbito penal a través de la ayuda de una tercera

33 CONSEJO ECONÓMICO Y SOCIAL DE NACIONES UNIDAS, 2016/17, recomendación de la Comisión de Prevención del Delito y Justicia Penal (E/2016/30), Naciones Unidas. Disponible en: https://www.refworld.org/cgi-bin/texis/vtx/rwmain/ opendocpdf.pdf?reldoc $=$ y\&docid $=57 \mathrm{c} 57 \mathrm{edc} 4$

${ }^{34}$ CONSEJO ECONÓMICO Y SOCIAL DE NACIONES UNIDAS, 2002/12 Principios básicos para la aplicación de programas de justicia restitutiva en materia penal, Naciones Unidas, 7 de enero de 2002. Disponible en: https://www.unodc.org/pdf/crime/ commissions/11comm/5add1s.pdf

35 OFICINA DE LAS NACIONES UNIDAS CONTRA LA DROGA Y EL DELITO (UNODC), Manual sobre programas de Justicia Restaurativa. Serie de Manuales sobre Justicia Penal, Viena, 2006, p. 8.

36 Directiva de la UE/29/2012 sobre los derechos de las víctimas en tal sentido que viene también siendo aplicable a los menores. 
parte imparcial". Se trata de una definición extrapolada de la Recomendación R(99)19 del Consejo de Europa, donde se alude al proceso de mediación en idéntico sentido. Esta Recomendación de 1999 viene a ser sustituida por la Recomendación de 2018 del Consejo de Europa sobre Justicia Restaurativa, la cual, pese a no ser jurídicamente vinculante, sí que constituye unos principios básicos para la Política criminal y un conjunto de orientaciones en la praxis de tales medios. En este sentido, la Recomendación CM/Rec (2018)8 del Comité de Ministros a los Estados miembros en materia de Justicia Restaurativa penal, advierte entre otras cuestiones, su labor tanto a la hora de complementar procesos penales como su papel alternativo a los mismos, considerando además como imprescindible la inclusión de otros agentes a lo largo del proceso (p.ej., otras personas afectadas además de la víctima, comunidad, etc.).

Conforme a dicha última Recomendación de 2018/8, y siguiendo a autores como Varona y Tamarit, lo cierto es que, si bien los procesos restaurativos han tenido un desarrollo muy lento en España, el impacto de la citada Recomendación "debería tener un impacto positivo en el desarrollo de la justicia restaurativa en España (...). La Ley debería contener asimismo una lista abierta de procesos restaurativos, que incluya encuentros grupales restaurativos (conferencing), círculos de pacificación, círculos de apoyo y reconciliación y mediación entre víctima e infractor..." ${ }^{37}$.

Para finalizar, y en lo que atañe de manera específica a la figura de la víctima del delito o sujeto perjudicado, indica Aranda Jurado que su relevancia como objeto de actuación no viene a aparece hasta el año 1985 en el ya mencionado Congreso de Milán, concretamente por los debates que en dicho momento vienen a generarse en torno a tal figura en cuanto a su relación con la Justicia Restaurativa. Es más, tal y como refiere la autora, se empieza a abogar por "otras formas de resolución de conflictos distintas al procedimiento judicial, los programas de mediación, conciliación y arbitraje (...) dentro del sistema judicial" ${ }^{38}$. En esta línea, no es de extrañar que las primeras consideraciones de la Victimología como disciplina científica nazcan de la mano de distintos especialistas a mitad del s.XX ${ }^{39}$, así como de los distintos Simposios internacionales que, en

37 VARONA, G. y TAMARIT, J.M., "Sección especial: La Recomendación (2018) 8 del Consejo de Europa sobre justicia restaurativa en asuntos penales. El caso de Francia, Italia, Alemania, Suiza y España, Revista de Victimología 8, 2018, pp. 181 y ss.

${ }_{38}$ ARANDA JURADO, M., "La promoción de la Justicia Restaurativa en materia penal por Naciones Unidas a través de sus Congresos Internacionales", Revista Boliviana de Derecho 27, 2019, pp. 552-575.

39 Vid. más información en: MORILLAS FERNÁNDEZ, D.L., PATRÓ HERNÁNDEZ, R.M. y AGUILAR CÁRCELES, M.M., Victimología: Un estudio de la víctima y los procesos de victimización, Madrid, Dykinson, 2014, pp. 13 y ss. 
materia específica de Victimología, empiezan a consolidarse desde el año $1973^{40}$.

En definitiva, pueden hallarse diversos paralelismos entre la Justicia Restaurativa y los propios movimientos victimológicos, encontrando entre sus justificaciones principales tanto la preocupación la figura de la víctima como la participación de esta a lo largo de todo el proceso de justicia penal (p.ej. mejor asistencia, compensación adecuada, etc.) ${ }^{41}$. Conforme a ello, y tomando de nuevo como referencia la idea de la centralidad de la víctima como referencia en el proceso de Justicia Restaurativa —entendida dicha "centralidad" como foco de interés y demanda social a partir de los pensamientos delimitadores de la Justicia Restaurativa-, refiere Zehr que la Justicia Restaurativa es la lente para comprender el delito como una violación de las personas y de sus relaciones, en lugar de una violación del Estado, donde el daño necesita ser resarcido ${ }^{42}$. No obstante, existen quienes informan del riesgo que dentro del Sistema de Justicia Penal pudiera tener la aplicación de la Justicia Restaurativa, pudiendo orientar la práctica más hacia la figura del delincuente (p.ej. reintegración, evitación de reincidencia, etc.) que al de la víctima, principalmente cuando se viera afectada la situación legal de aquél ${ }^{43}$.

\section{1. Ámbito nacional}

En lo que compete al ámbito del derecho interno, habría que diferenciar entre las disposiciones que atañen al Derecho Penal de adultos, y las que competen a dicha legislación en el colectivo de menores. Comenzando por el primero de ellos, lo cierto es que son distintas disposiciones las que, dentro del Código Penal, aluden a la reparación del daño en la víctima. Así por ejemplo, dentro del catálogo de las circunstancias modificativas de la responsabilidad criminal, indica el art. 21.5 CP que será una circunstancia atenuante "la de haber procedido el culpable a reparar el daño ocasionado a la víctima, o disminuir sus efectos, en cualquier momento del procedimiento y con anterioridad a la celebración del acto del juicio oral". Igualmente, en relación a la suspensión de la ejecución de las penas privativas de libertad, refiere el art. $80.1 \mathrm{CP}$ que se podrá apreciar dicha figura cuando se aprecien una sería de circunstancias, entre las que destaca el "particular esfuerzo para reparar el daño causado", detallando el legislador expresamente lo que compete a la mediación en

40 Ibidem, pp. 8 y ss.

41 VANFRAECHEM, I. \&, D. BOLÍVAR, "Restorative justice and victims of crime", in I. Vanfraechem, D. Bolívar and I. Aertsen (Eds.), Victims and restorative justice, Oxfordshire, Routledge, 2015, pp.51 y ss.

42 ZEHR, Changing leses: a new focus... cit., p.186.

43 JOHNSTONE, G. \& VAN NESS, D., “The meaning of restorative justice”, in G. Johnstone and D. Van Ness (Eds.), Handbook of restorative justice, Collumpton, Willan Publishing, 2007, pp.5-23. 
el apartado primero del art. 84.1 CP al indicar que se podrá condicionar dicha suspensión al cumplimiento de alguna prestación o medida, concretamente al "cumplimiento del acuerdo alcanzado por las partes en virtud de mediación" 44 . Como puede apreciarse de la lectura anterior, todas las menciones indicadas aluden a la Parte General del Derecho Penal, no indicando con ello su ausencia dentro de la Parte Especial, donde el legislador refiere, esta vez de manera expresa, en qué tipos penales la reparación a la víctima estaría reflejada como una atenuante específica dentro del propio tipo penal. En esta línea, podrían destacarse los delitos contra los recursos naturales y el medio ambiente (arts. 325 y ss.), reservándose el art. $340 \mathrm{CP}$ para la redacción de la reparación al indicar expresamente que "si el culpable de cualquiera de los hechos tipificados en este Título hubiera procedido voluntariamente a reparar el daño causado, los Jueces y Tribunales le impondrán la pena inferior en grado a las respectivamente previstas" 45 .

En lo que compete al colectivo de menores de edad, y dando ya paso al siguiente apartado, lo cierto es que en España no existe una regulación específica que contemple la mediación en materia penal, pese a advertir la propia Ley Orgánica 5/200, de Responsabilidad Penal de los Menores de Edad (LORPM), en su artículo 19, sobre los siguientes aspectos ${ }^{46}$ :

“1. También podrá el Ministerio Fiscal desistir de la continuación del expediente, atendiendo a la gravedad y circunstancias de los hechos y del menor, de modo particular a la falta de violencia o intimidación graves en la comisión de los hechos, y a la circunstancia de que además el menor se haya conciliado con la víctima o haya asumido el compromiso de reparar el daño causado a la víctima o al perjudicado por el delito, o se haya comprometido a cumplir la actividad educativa propuesta por el equipo técnico en su informe.

El desistimiento en la continuación del expediente sólo será posible cuando el hecho imputado al menor constituya delito menos grave o falta.

2. A efectos de lo dispuesto en el apartado anterior, se entenderá producida la conciliación cuando el menor reconozca el daño causado y se disculpe ante la víctima, y ésta acepte sus disculpas, y se entenderá por reparación el compromiso asumido por el menor con la víctima o perjudicado de realizar determinadas acciones en beneficio de aqué-

44 Inclusión por la reforma efectuada por Ley Orgánica 1/2015, de 30 de marzo, por la que se modifica el Código Penal.

45 Baste señalar la particularidad que define a los delitos de calumnia e injuria, cuya naturaleza entre lo civil y lo penal, así como su caracterización específica, hacen que por medio de un procedimiento especial tenga cabida para su solvencia un acto de conciliación (arts. 804 y ss. Ley de Enjuiciamiento Criminal).

${ }_{46}$ Ley Orgánica 5/2000, de 12 de enero, reguladora de la responsabilidad penal de los menores. https://www.boe.es/buscar/act.php?id=BOE-A-2000-641 
llos o de la comunidad, seguido de su realización efectiva. Todo ello sin perjuicio del acuerdo al que hayan llegado las partes en relación con la responsabilidad civil.

3. El correspondiente equipo técnico realizará las funciones de mediación entre el menor y la víctima o perjudicado, a los efectos indicados en los apartados anteriores, e informará al Ministerio Fiscal de los compromisos adquiridos y de su grado de cumplimiento.

4. Una vez producida la conciliación o cumplidos los compromisos de reparación asumidos con la víctima o perjudicado por el delito o falta cometido, o cuando una u otros no pudieran llevarse a efecto por causas ajenas a la voluntad del menor, el Ministerio Fiscal dará por concluida la instrucción y solicitará del Juez el sobreseimiento y archivo de las actuaciones, con remisión de lo actuado.

5. En el caso de que el menor no cumpliera la reparación o la actividad educativa acordada, el Ministerio Fiscal continuará la tramitación del expediente.

6. En los casos en los que la víctima del delito o falta fuere menor de edad o incapaz, el compromiso al que se refiere el presente artículo habrá de ser asumido por el representante legal de la misma, con la aprobación del Juez de Menores".

Conforme a ello, y siendo el texto literal de la propia LORPM $^{47}$ expuesto con anterioridad, se deduce que, en relación con el sobreseimiento del expediente por conciliación o reparación entre el menor y la víctima, el Ministerio Fiscal, como garante de los derechos del menor, podrá desistir de la continuación del expediente atendiendo a las circunstancias de los hechos, siempre que hubiera habido conciliación y compromiso de reparación del daño o cumplimiento de actividades educativas de formación. Así pues, podría decirse que se contempla, por un lado, la conciliación y, por otro lado, la reparación del daño, pudiendo en este caso abogar por la mediación penal. En esta línea, siguiendo a autoras como Domingo De la Fuente, indica la misma que dicha medida de resolución alternativa de conflictos "la pueden hacer los equipos técnicos o bien se puede externalizar en una organización no lucrativa" ${ }^{48}$, siendo la consecuencia para los menores que participen en el proceso de restauración el archivo de la causa. Igualmente, realiza la autora una crítica en cuanto a la "la distinción entre conciliación y reparación del daño, ya que se aso-

47 Nótese la ausencia de actualización en cuanto a supresión de las faltas en los preceptos reseñados.

48 DOMINGO DE LA FUENTE, V., "Contexto teórico-práctico de la justicia restaurativa en Europa con especial atención a España”, en V. Domingo (Coord.) et al., Una mirada hacia la Justicia Restaurativa: Recuperando el derecho perdido, Criminología y Justicia $\mathrm{N}^{\circ} 4$, 2012, pp. 70 y ss. 
cia conciliación con petición de disculpas por el infractor y mediación penal a reparación del daño, sin embargo, dentro de un proceso de mediación penal se puede contemplar las disculpas del infractor", a lo que añade, "tampoco se puede equiparar del todo reparación y mediación penal. (...) que a través de procesos restaurativos como mediación penal se puede lograr una reparación del daño cualificada y más satisfactoria para ambas partes, las cuales habrán participado y decidido de mutuo acuerdo en qué consistirá la reparación" ${ }^{49}$. En este orden de cosas, lo que viene a transmitir el error al poder comprender que la mediación no comportaría disculpas, así como al hecho de identificar todo proceso de reparación del daño con la mediación, lo cual sería un claro error.

Pese a todo lo anterior, lo cierto es que desde la promulgación de la LORPM, así como gracias al avance legislativo de los últimos años, cada vez se ha visto una apuesta mayor por el empleo de las medidas alternativas de resolución de conflictos en el ámbito de la Administración; así pues, como refiere Jericó Ojer, al ser el deber del Derecho Penal el de regular los conflictos generados en población infanto-juvenil, "lo que condiciona la respuesta penal debe tener también características muy especiales" ${ }^{50}$. En cualquiera de los casos, si bien dicha respuesta debe tener por objeto la posible solvencia de ciertos casos de una forma alternativa a la misma, lo cierto es que debe extremarse la cautela en aquellas posibles situaciones en las que pudiera llegar a desvirtuarse la propia esencia de la Justicia Restaurativa. De este modo, cuando el fundamento de la reparación y conciliación no es otro que el de agilizar el número de casos, o el hecho de economizarlos, la propia esencia de dichas medidas alternativas degeneraría. Ate ello, refiere Bernuz Beneitez que podría "resultar interesante analizar la legislación española para ver si sus propuestas están más relacionadas con la realización del principio de oportunidad, de intervención mínima o de desjudicialización que con la concreción de los valores de una Justicia Restaurativa que apuesta por una forma distinta de entender el delito y de hacer justicia" ${ }^{51}$.

Por último, cabe señalar que desde el punto de vista victimal se han ido haciendo escuetas alusiones a los procesos de Justicia Restaurativa. Específicamente, se niega su viabilidad ante los supuestos de violencia de género, pues tal y como refiere la Ley orgánica 1/2004, de 28 de diciembre, de Medidas de Protección Integral contra la Violencia de Género en su artículo 44 la prohibición de mediar se extenderá a aquellos supuestos en los que son competentes para conocer del proceso los Juzgados de

49 Ibidem, pp. 71 y ss.

50 JERICÓ OJER, L., "El impacto (probablemente no previsto) de la reforma del Código Penal operada por la LO 1/2015, de 30 de marzo, en el Derecho Penal de Menores", Revista Electrónica de Ciencia Penal y Criminología (RECPC), 20-24, 2018, pp. 2 y ss.

${ }^{51}$ BERNUZ BENEITEZ, M.J., "Las posibilidades de la Justicia Restaurativa en la Justicia de Menores (española)", Revista Electrónica de Ciencia Penal y Criminología (RECPC), 16-14, 2014, pp. 11 y ss. 
Violencia sobre la Mujer, tanto a nivel civil como penal. No obstante, esta postura viene a cuestionarse por parte de la doctrina, la cual viene a advertir sobre la viabilidad de la mediación como modelo alternativo de resolución de conflictos en el ámbito familiar. Pese a ello, lo cierto es que, sea de uno u otro modo, deberán evaluarse las circunstancias de cada caso en cuestión.

Por otro lado, y destacando en esta ocasión la Ley 4/2015, de 27 de abril, por la que se aprueba el Estatuto de la Víctima del Delito (EVD), lo cierto es que la Ley de 2015 incluye la una referencia expresa a la actuación de los Servicios propios de Justicia Restaurativa, indicando textualmente que "el Estatuto supera las referencias tradicionales a la mediación entre víctima e infractor y subraya la desigualdad moral que existe entre ambos", a lo que añade, "la actuación de estos servicios se concibe orientada a la reparación material y moral de la víctima, y tiene como presupuesto el consentimiento libre e informado de la víctima y el previo reconocimiento de los hechos esenciales por parte del autor. (...) la posible actuación de los servicios de Justicia Restaurativa quedará excluida cuando ello pueda conllevar algún riesgo para la seguridad de la víctima o pueda ser causa de cualquier otro perjuicio". Igualmente, el propio Estatuto contempla un conjunto de requisitos de acceso a los citados Servicios (art. 15 EVD), a saber:

a) El reconocimiento de la responsabilidad por parte del victimario.

b) La manifestación expresa del consentimiento de la víctima tras haber recibido la información pertinente sobre este tipo de procesos.

c) El consentimiento del infractor.

d) La ausencia de riesgo de su puesta en práctica para la seguridad de la víctima, así como ausencia de peligro alguno de que su desarrollo pueda causar revictimización (p.ej., perjuicios morales o materiales).

e) La inexistencia de prohibición para el tipo de ilícito cometido.

A todo lo anterior se añade expresamente la confidencialidad de lo debatido durante el proceso, así como la sujeción a secreto profesional por parte de los profesionales. De la misma forma, se indica expresamente la posibilidad de la revocación del consentimiento durante cualquier momento del procedimiento.

Visto todo lo anterior, y ya para finalizar, lo cierto es que, frente a otras ramas del Derecho, como sería el caso del ámbito civil y mercantil ${ }^{52}$, la mediación en el ámbito penal quedaría todavía vacía de conteni-

52 Vid. más información en la Ley 5/2012, de 6 de julio, de Mediación en Asuntos Civiles y Mercantiles. 
do en cuanto a su aplicabilidad y directrices en la práctica profesional. Pese a ello, la demanda actual en cuanto a la necesidad de una mayor contemplación de las resoluciones alternativas de conflictos, principalmente en el ámbito de los menores de edad, hace que se haya abierto un campo de actuación que reclama su aplicación como una vía que permite "asegurar" la integración social de los más jóvenes desde un punto de vista más humanitario y menos perturbador; todo ello teniendo presente la salvaguarda en todo momento de las garantías y derechos de las víctimas como colectivo perjudicado.

\section{ACTUACIÓN SOBRE COLECTIVOS ESPECIALMENTE VULNERABLES: REFERENCIA A LOS MENORES DE EDAD}

Desde el punto de vista victimológico, los menores, incapaces o personas con algún tipo de enfermedad mental, así como los ancianos y las mujeres representarían colectivos de especial vulnerabilidad. Siguiendo a Doerner y Lab 53, la vulnerabilidad haría referencia a la "facilidad que presenta el sujeto para ser victimizado y el impacto que el crimen le ha producido o generado", entendiéndose tal impacto en distintos ámbitos de la vida del sujeto (personal, interpersonal o social en general, laboral, escolar, etc.). De la misma forma, la vulnerabilidad podría venir también delimitada por factores situacionales y del estilo de vida, como sería la pobreza o la encarcelación ${ }^{54}$. Dicho ello, las medidas de suspensión serían consideradas de vital importancia para cuatro grupos poblacionales de individuos, esto es, menores, enfermos mentales, drogodependientes y mujeres ${ }^{55}$. No obstante, ello no quita que los principios básicos de la Justicia Restaurativa deban de intentar promoverse como alternativa al colectivo de hombres adultos, siendo en su mayoría los que ocupan el groso de la institución penitenciaria.

Los menores víctimas representan una población de especial vulnerabilidad, tratándose de un colectivo que demanda un especial cuidado por parte de todos los profesionales que intervienen en el proceso judicial ${ }^{56}$. En este sentido, se hace más evidente que nunca el papel de la Adminis-

53 DOERNER, W.G. \& Lab, S.P., Victimology (5 $5^{\text {th }}$ Ed.), Cincinnati, OH: LexisNexis, 2008, p.293.

${ }_{54}$ GARLAND, T. \& POLICASTRO, C., "Victimization of the vulnerable", in T.N. Richards and C.D. Marcus, Sexual victimization: Then and now, London, SAGE publications, 2015, p.153.

55 OFICINA DE LAS NACIONES UNIDAS CONTRA LA DROGA Y EL DELITO (UNODC), Manual sobre programas... cit., 2010, p. 2.

${ }_{56}$ Más información en: BELOFF, M., KIERSZENBAUM, M. \& TERRAGNI, M., "La justicia juvenil y el juicio por jurados", Revista de Derecho Penal y Criminología, Núm. 10, 2017, 153-168, y MONTOLLI, C.A. \& DA CRUZ, M.A., "Justiça restaurativa e maioridade 
tración, y de sus profesionales, como garante de la población infanto-juvenil. Además, precisamente, dentro del citado cometido de tutela de los derechos de los menores de edad por parte de la Administración, podrían decirse que existen diversos tratados y declaraciones internacionales que reconocen la importancia de promover y salvaguardar el bienestar y los intereses de los niños, cuya especial complejidad no solo vendría delimitada por aspectos que competen al mismo entramado judicial, sino por comprender la limitación de las capacidades por la etapa del desarrollo vital en la que se encuentran, la mayor vulnerabilidad que presentan, y la dependencia de terceras personas.

La Convención de Naciones Unidas sobre los Derechos del Menor de 1989 (Convention on the Rights of the Childs, CRC) representa la continuación de la evolución de los derechos del hombre, pero en esta ocasión sobre dicho colectivo de especial vulnerabilidad. Concretamente, supone un aliciente de cara al respeto y consideración a nivel mundial de los derechos del niño, pues aún y cuando muchos países ya gozaban de leyes que protegían la infancia, algunos no las venían respectando. Así pues, el citado Catálogo de Derechos supone reconocer que los niños (seres humanos menores de 18 años) son individuos con derecho de pleno desarrollo físico, mental y social, y con derecho a expresar libremente sus opiniones, promoviendo y protegiendo de este modo los derechos de la infancia.

Dicho lo anterior, y rescatando la afirmación del Plan de Acción de la Cumbre Mundial a favor de la Infancia, de 30 de septiembre de 1990, "no hay causa que merezca más alta prioridad que la protección y el desarrollo del niño, de quien dependen la supervivencia, la estabilidad y el progreso de todas las naciones y, de hecho, de la civilización humana», lo que ponía de manifiesto, ya hace más de treinta años, la necesidad de la salvaguardar del menor en pro de la salvaguarda social. A colación de lo anterior, se entiende en estos casos la amplitud de la delimitación del "niño" al colectivo de menores de edad, principalmente en lo que atañe a la esfera de la actuación en la etapa adolescente-juvenil, donde la legislación internacional no debe pasar inadvertida a la nueva realidad social: el incremento de la delincuencia juvenil en los últimos años y su potenciación por las TIC's.

Dentro de este ámbito, el Observatorio Internacional de Justicia Juvenil (OIJJ) viene comprometiéndose desde hace años con los asuntos jurídico-penales en los que los menores se ven involucrados, señalando de manera específica la necesidad de considerar los siguientes textos

penal: efectivação do Estatuto da Criança e do Adolescente e Justiça Humanizada", Revista de Derecho Penal y Criminología, Núm. 10, 2017, 140-152. 
internacionales en lo que a la intervención con la citada población hace referencia ${ }^{57}$ :

- Declaración Universal de Derechos Humanos (DUDH), es decir, documento adoptado por Naciones Unidas en su Resolución 217 A(III) en diciembre de 1948 en París en el cual se recogen 30 Artículos de los derechos humanos considerados esenciales.

- Convención sobre los Derechos del Niño o Declaración de Ginebra, adoptada por unanimidad por la Asamblea General de las Naciones Unidas en su Resolución 44/25 de 20 de noviembre de 1989 , en la que expresamente viene a identificarse al menor con un individuo al que se le reconoce su pleno desarrollo físico-psicosocial, así como su derecho a expresar con libertad sus propias opiniones $^{58}$.

- Directrices de las Naciones Unidas para la prevención de la delincuencia juvenil. Las también conocidas como "Directrices de Riad" parten en su primer principio de la siguiente afirmación, esto es, "la prevención de la delincuencia juvenil es parte esencial de la prevención del delito en la sociedad. Si los jóvenes se dedican a actividades lícitas y socialmente útiles, se orientan hacia la sociedad y enfocan la vida con criterio humanista, pueden adquirir actitudes no criminógenas", indicando expresamente en su segundo principio que "para poder prevenir eficazmente la delincuencia juvenil es necesario que toda la sociedad procure un desarrollo armonioso de los adolescentes, y respete y cultive su personalidad a partir de la primera infancia" ${ }^{59}$. Como puede apreciarse, resulta especialmente interesante el planteamiento al que reiteradamente recurre Naciones Unidas, resaltando la necesidad de prevención del delito en los más jóvenes para evitar el desarrollo y cronicidad de la carrera criminal, la importancia de desarrollar comportamientos no criminógenos, y la relevancia de intervenir en las primeras etapas del ciclo vital, pues la intervención temprana es precisamente la mayor de las soluciones. En este mismo sentido, cuando indica que "la sociedad procure un desarrollo armonioso de los adolescentes", alude especialmente a

57 Información disponible en la página web del Observatorio Internacional de Justicia Juvenil (OIJJ), enlace: http://www.oijj.org/es/que-hacemos

58 Dado el interés que dicha declaración despierta, puede consultarse más información sobre la misma tanto en la siguiente dirección web: https://www.un.org/es/ events/childrenday/pdf/derechos.pdf, como en artículos de investigación (vid. a modo de ejemplo: TIANA FERRER, A., "Declaración de los Derechos del Niño y Convención sobre los Derechos del Niño", Transatlántica de Educación, Vol. V, 2008, pp. 95-112).

59 Directrices de las Naciones Unidas para la prevención de la delincuencia juvenil (Directrices de Riad), adoptadas y proclamadas por la Asamblea General en su resolución 45/112, de 14 de diciembre de 1990. Vid.: https://www.ohchr.org/SP/ProfessionalInterest/ Pages/PreventionOfJuvenileDelinquency.aspx. 
la necesaria adecuada actuación de los agentes informales en el proceso de socialización, de manera que la familia o escuela, entre otros agentes, se constituyen como medios o herramientas de control social informal del delito, de forma qua la actuación por parte de los medios de control social formal solo se llevará acabo cuando la primera haya fracasado.

- Reglas mínimas de las Naciones Unidas para la administración de la justicia de menores o Reglas de Beijing las cuales, en consonancia con las "Directrices de Riad", advierten sobre la necesidad de promover "el interés del menor y de su familia, (...) fomentando, durante el período de edad en que el menor es más propenso a un comportamiento desviado, un proceso de desarrollo personal y educación lo más exento de delito y delincuencia posible" ${ }^{60}$. De esta forma, queda de nuevo patente la relevancia del ámbito familiar como factor de protector en la prevención de la conducta antisocial de las primeras etapas, de manera que el aseguramiento de la armonía dentro de dicho entorno, junto con la presencia de unos estilos parentales adecuados y un ambiente saludable, actuará como factor repelente de la carrera delincuencial.

- Reglas de Tokio, destacando entre sus cometidos la promoción de las medidas no privativas de libertad, así como el fomento de la participación de la comunidad en el tratamiento del delincuente ${ }^{61}$.

- Observación General No 10 (2007) de Naciones Unidas sobre los derechos del niño en la justicia de menores, del Comité de los Derechos del Niño, en la cual hace mención expresa a la necesidad de promover el pleno desarrollo de los menores y orientarlo al adecuado respecto a los derechos humanos y libertades fundamentales. En este sentido, se alude a la necesidad de una crianza en unas condiciones normalizadas capaces de evitar riesgos futuros para el desarrollo criminal, destacando expresamente la importancia de una política de menores acompañada de medidas de prevención de la delincuencia en los más jóvenes, donde la prestación de apoyo a familias en riesgo debe considerarse de atención prioritaria ${ }^{62}$.

${ }^{60}$ Reglas mínimas de las Naciones Unidas para la administración de la justicia de menores (Reglas de Beijing). Adoptadas por la Asamblea General en su resolución 40/33, de 28 de noviembre de 1985. Vid.: https://www.bienestaryproteccioninfantil.es/imagenes/ tablaContenidos03SubSec/Reglas_minimas_NU_Beijing.pdf

${ }_{61}$ Reglas mínimas de las Naciones Unidas sobre las medidas no privativas de la libertad (Reglas de Tokio). Adoptadas por la Asamblea General en su resolución 45/110, de 14 de diciembre de 1990. https://www.bienestaryproteccioninfantil.es/imagenes/ tablaContenidos03SubSec/reglas\%20tokio2.pdf

${ }_{62}$ Observación General N ${ }^{\mathrm{O}} 10$ (2007) de Naciones Unidas sobre Los derechos del niño en la justicia de menores, del Comité de los Derechos del Niño, 25 de abril de 2007. Disponible en: https://www2.ohchr.org/english/bodies/crc/docs/crc.c.gc.10_sp.pdf 
Unido a lo anterior, una de las acciones del Consejo de Europa de mayor actualidad alude precisamente a las pautas del Consejo de Europa para respetar, proteger y cumplir los derechos del niño en el entorno digital, las cuales refieren expresamente la necesidad de evaluar las leyes y políticas relacionadas con el entorno digital en base al impacto que su implementación pudiera tener en el disfrute de los derechos humanos y las libertades de los menores. De la misma manera, señala que un marco legal integral de actuación debe comprender tanto medias preventivas que sean tanto capaces de proteger a los menores en dicho entorno, como proporcionar las herramientas adecuadas de actuación para padres y cuidadores. Así pues, en este conjunto de mecanismos se pone de manifiesto la necesidad de "prohibir toda forma de violencia, explotación y abuso", así como la necesidad de establecer mecanismos de "información, denuncia y quejas para niños (...), combatir la impunidad"63.

En dicha línea, y tomando como referencia la definición de "inteligencia artificial" (IA) ofrecida por la Comisión Europea, esto es, "sistemas que manifiestan un comportamiento inteligente, pues son capaces de analizar su entorno y pasar a la acción -con cierto grado de autonomía-con el fin de alcanzar objetivos específicos. (...) pueden consistir simplemente en un programa informático (p. ej. asistentes de voz, programas de análisis de imágenes, motores de búsqueda, sistemas de reconocimiento facial y de voz)" ${ }^{64}$, no es de extrañar que desde los organismos internacionales se venga prestando especial atención al entorno digital, principalmente en lo que respecta a los menores de edad por su especial vulnerabilidad. Así pues, y pese a afirmar que la población juvenil y adolescente es ahora la que, quizás con mayor seguridad, venga a conocer cómo desenvolverse a través de Internet, lo cierto es que dicho colectivo, al igual que sucede con los más pequeños, no queda exento del peligro inherente al propio ciberespacio, considerándose en cualquier caso como blancos preferentes. Precisamente en relación con este último punto, y volviendo de nuevo al Consejo de Europa, no es de extrañar que recientemente venga a publicar las citadas pautas en relación a la necesidad de considerar que el desarrollo y proliferación de las nuevas tecnologías, unido a su uso inadecuado (p.ej., por falta de medidas de actuación, por propio desconocimiento del menor), puede afectar de manera negativa a su bienestar físico, psíquico y emocional. En este

${ }^{63}$ COUNCIL OF EUROPE, Guidelines to respect, protect and fulfil the rights of the child in the digital environment, Building a Europe for and woth children, Recommendation CM/ Rec(2018)7 of the Committee of Ministers 2018, pp. 22 y ss.

Disponible en: https://rm.coe.int/guidelines-to-respect-protect-and-fulfil-the-rights-ofthe-child-in-th/16808d881a

${ }^{64}$ COMISIÓN EUROPEA, Inteligencia artificial para Europa, Comunicación de la Comisión al Parlamento Europeo, al Consejo, al Comité Económico y Social Europeo y al Comité de las Regiones, Bruselas, 25.4.2018 COM(2018) 237 final [SWD(2018)137final l] pp. 1 y ss. Disponible en: http://ec.europa.eu/transparency/regdoc/rep/1/2018/ES/COM2018-237-F1-ES-MAIN-PART-1.PDF 
sentido, y partiendo de la base de que "cualquier medida de protección deber tener en cuenta el interés superior y las capacidades de evolución del niño", se viene a considerar la necesidad de tener en cuenta unas mayores precauciones en base a la presencia de un conjunto de riesgos bastante presentes en la esfera del ciberespacio. Concretamente, se alude a los "riesgos de contacto", "riesgos de contenido", "riesgos de conducta", y "riesgos para la salud", siendo las diferencias las que a continuación se mencionan, a saber 65:

a) Conductas de explotación y abuso sexual, solicitud con fines sexuales, y "reclutamiento" online de niños para la comisión de delitos, sea para participar en movimientos políticos o religiosos extremistas, como para fines de tráfico. Lo que viene a comprenderse bajo la acepción de "riesgos de contacto".

b) El favorecimiento de una visión degradante y estereotipada de los menores, así como una "hipersexualización" de mujeres y niños en particular, la inducción hacia la realización de conductas autolesivas (ideas suicidas), el empleo de expresiones degradantes, discriminatorias o racistas, o las mismas conductas apologéticas. Descripción que viene a comprenderse bajo la acepción de "riesgos de contenido".

c) El bullying, hostigamiento, acoso, distribución de imágenes sexuales son consentimiento, extorsión, incitación al odio, piratería, apuestas, descargas ilegales u otros ilícitos contra la propiedad intelectual, explotación comercial, etc. Todo lo cual viene a ampararse bajo la denominación genérica de "riesgos de conducta".

d) El uso excesivo de las nuevas tecnologías ("adicción”), falta de sueño y daños físicos (la realización de la autolesión antes mencionada —no su inducción-, así como el propio suicidio). Lo cual se ubicaría para la denominación "riesgos para la salud".

Con toto ello, se hace imprescindible respectar los derechos de los menores en los distintos procedimientos en los que sean parte, tanto como víctima como en la figura del victimario. En este sentido, y partiendo de dicha finalidad garantista respecto de los menores, se presenta a continuación una tabla a modo de síntesis donde se recogen algunos de los aspectos comunes entre los Derechos Humanos, los principios de la Justicia Restaurativa y los principios de la Justicia Juvenil que atañen a tal colectivo, esto es:

${ }^{65}$ COUNCIL OF EUROPE, Guidelines to respect, protect ... cit., pp. 19 y 20. 


\section{Tabla 3. Aspectos comunes entre los Principios de los Derechos Humanos, los Principios de la Justicia Restaurativa, y los Principios de la Justicia Juvenil ${ }^{66}$.}

\begin{tabular}{|c|c|c|}
\hline $\begin{array}{c}\text { Principios de los } \\
\text { Derechos Humanos }\end{array}$ & $\begin{array}{c}\text { Principios de la Justicia } \\
\text { Restaurativa }\end{array}$ & $\begin{array}{c}\text { Principios de la Justicia } \\
\text { Juvenil }\end{array}$ \\
\hline $\begin{array}{l}\text { Dignidad humana y } \\
\text { respeto }\end{array}$ & Respeto y dignidad & Dignidad humana \\
\hline Igualdad & Igualdad y diversidad & Justicia social \\
\hline Justicia y Legalidad & $\begin{array}{l}\text { Legalidad, Justicia, } \\
\text { proporcionalidad y } \\
\text { proceso digno }\end{array}$ & Humanidad \\
\hline Autonomía & $\begin{array}{l}\text { Participación en la toma } \\
\text { de decisiones }\end{array}$ & Integridad \\
\hline $\begin{array}{l}\text { Equidad y } \\
\text { proporcionalidad }\end{array}$ & $\begin{array}{l}\text { Reparación y } \\
\text { restauración }\end{array}$ & $\begin{array}{c}\text { Competencia } \\
\text { (posibilidad de asumir } \\
\text { acciones) }\end{array}$ \\
\hline $\begin{array}{l}\text { Hermandad y } \\
\text { solidaridad }\end{array}$ & $\begin{array}{l}\text { Hermandad y } \\
\text { solidaridad }\end{array}$ & $\begin{array}{l}\text { Hermandad y } \\
\text { solidaridad }\end{array}$ \\
\hline $\begin{array}{c}\text { Efectividad, } \\
\text { transparencia y } \\
\text { confidencialidad }\end{array}$ & Voluntariedad & Voluntariedad \\
\hline $\begin{array}{l}\text { Obligaciones } \\
\text { comunitarias y } \\
\text { responsabilidad } \\
\text { individual }\end{array}$ & Confidencialidad & $\begin{array}{l}\text { Autonomía y } \\
\text { responsabilidad } \\
\text { individual }\end{array}$ \\
\hline $\begin{array}{l}\text { Libertad de elección, } \\
\text { de decisión, sin } \\
\text { restricciones, etc. } \\
\text { (Freedom o facultad de } \\
\text { actuar de un modo otro } \\
\text { bajo una decisión libre) }\end{array}$ & $\begin{array}{l}\text { Libertad de elección, } \\
\text { de decisión, sin } \\
\text { restricciones, etc. } \\
\text { (Freedom o facultad de } \\
\text { actuar de un modo otro } \\
\text { bajo una decisión libre) }\end{array}$ & $\begin{array}{l}\text { Libertad de elección, } \\
\text { de decisión. }\end{array}$ \\
\hline
\end{tabular}

Algunos de estos principios, si no la mayoría de ellos, vienen a estar reflejados en los tratados internacionales ya mencionados con anterioridad, siendo su principal interés el hecho de establecer un punto de refe-

66 GAVRIELIDES, T., "Bridging restorative justice and human rights for youth justice", in T. Gavrielides (Ed.), Rights and restoration within youth justice, Sitter Publications: Canada, 2012, pp.33 y ss. 
rencia en la práctica judicial juvenil. Concretamente, un resumen de ello y de su relevancia se expone en la siguiente tabla:

\section{Tabla 4. Tratados de Naciones Unidas sobre la justicia juvenil y su relevancia para los Derechos Humanos y para el ámbito de la Justicia Restaurativa ${ }^{67}$.}

\begin{tabular}{|c|c|}
\hline Tratado de Naciones Unidas y año & $\begin{array}{c}\text { Relevancia para el ámbito de los } \\
\text { Derechos Humanos y Justicia } \\
\text { Restaurativa }\end{array}$ \\
\hline $\begin{array}{l}\text { Reglas de Beijing, } 1985 \\
\text { Reglas mínimas de las Naciones } \\
\text { Unidas para la administración de la } \\
\text { justicia de menores }\end{array}$ & $\begin{array}{c}\text { Derechos del menor, bienestar, } \\
\text { derecho a la representación, libertad } \\
\text { etc. }\end{array}$ \\
\hline $\begin{array}{c}\text { Directrices de Riad, } 1990 \\
\text { Directrices de las Naciones Unidas } \\
\text { para la prevención de la delincuencia } \\
\text { juvenil }\end{array}$ & $\begin{array}{l}\text { Intervención temprana para evitar } \\
\text { delincuencia juvenil }\end{array}$ \\
\hline $\begin{array}{l}\text { Reglas de La Habana, } 1990 \\
\text { Reglas de las Naciones Unidas para } \\
\text { la protección de los menores privados } \\
\text { de libertad }\end{array}$ & $\begin{array}{l}\text { Desviación de los procedimientos } \\
\text { penales, libertad, justicia y dignidad }\end{array}$ \\
\hline $\begin{array}{c}\text { Reglas Tokio, } 1990 \\
\text { Reglas mínimas de las Naciones } \\
\text { Unidas sobre las medidas no } \\
\text { privativas } \\
\text { de la libertad }\end{array}$ & Mayor implicación en la comunidad \\
\hline $\begin{array}{c}\text { Directrices de Viena, } 1997 \\
\text { Directrices de Acción sobre el Niño } \\
\text { en el Sistema de Justicia Penal }\end{array}$ & $\begin{array}{c}\text { Derechos de los menores, } \\
\text { prevención, desviación, priorizar } \\
\text { las causas sociales del delito, } \\
\text { dignidad humana }\end{array}$ \\
\hline
\end{tabular}

En el contexto de la victimización infantil, tanto la protección del menor como la prevención de daños o de revictimizaciones futuras se establecen como propósito esencial; ahora bien, siguiendo a Gal, cuando se habla de derechos en la infancia y Justicia Restaurativa, ¿no sería más realista hablar de las obligaciones del Sistema de Justicia y de la sociedad con los menores, o de sus necesidades dentro del proceso, que

67 Ibidem, p.34. 
de la teorización de los derechos de los mismos? ${ }^{68}$ Dicho de otro modo, teorizar, defender o representar los derechos de los menores sin generar ningún tipo de obligación judicial ni social respecto a sus necesidades, conduciría a su plena desprotección.

Conforme a ello, establece el mismo autor una representación de los factores esenciales a considerar dentro del proceso, así como de su interrelación e integración entre los que serían unos modelos de actuación más jurídicos y otros más propios de una intervención psicosocial. De esta forma, se presenta en la siguiente imagen la importancia de encuentro-conciliación entre las necesidades y los derechos de los menores, establecidas sobre las premisas de control y mantenimiento de la seguridad y bienestar a lo largo de todo el proceso judicial, incluso en aquellos momentos en los que se trata de procesos criminológicamente complejos.

\section{Imagen 1. Integración de los modelos psicosociales y legales: modelo sobre las necesidades-derechos de los menores ${ }^{69}$.}

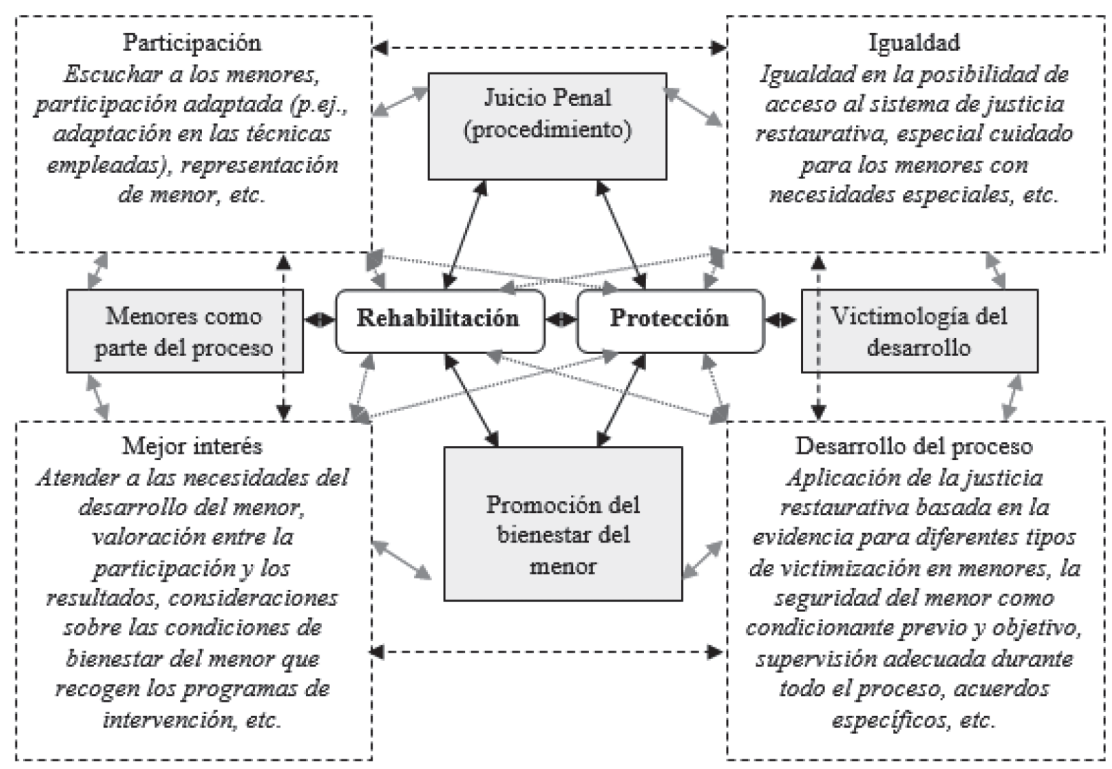

Las propias premisas de la Justicia Restaurativa se reflejan como experiencias de resolución de conflictos dentro del ámbito escolar, concretamente, su práctica en dicho contexto no solo se establece en la búsque-

68 GAL, T., Child victims and restorative justice, Oxford: Oxford University Press, 2011, p.13.

69 Ibidem, p.7. 
da de soluciones constructivas a problemas más disciplinarios, sino en crear escuelas más seguras y pacíficas. Así, como indica Walgrave, dentro de un ambiente pedagógico —explícitamente hablando-, todas las intervenciones escolares tienen como objetivo desarrollar un conjunto de competencias y habilidades en los estudiantes orientada a la resolución de conflictos de una manera más constructiva a través de la inteligencia emocional y social ${ }^{70}$. En este sentido, uno de los ejemplos más claros y actuales se observa en la posibilidad de aplicación de las premisas de la Justicia Restaurativa en los casos de bullying entre menores ${ }^{71}$. Siguiendo a autores como Morrison, en la escuela estaría representaría la sociedad en miniatura y las personas en proceso de aprendizaje hacia futuros ciudadanos, de manera que como se gestionen las escuelas se podrá determinar cómo próximas generaciones funcionarán en el futuro ${ }^{72}$. En la misma línea, González, Etow y De La Vega afirman que "la Justicia Restaurativa basada en la escuela prioriza el crecimiento individual y comunitario y las relaciones receptivas, contribuyendo a una cultura escolar general más segura y saludable", de esta forma señalan que la prevención e intervención, a dicho nivel, tiene como objetivo prioritario modificar las relaciones de interacción entre estudiantes y adultos mediante el empleo de prácticas diversas como conferencias restaurativas y procesos de mediación de víctimas y delincuentes lo cual, tal y como aseguran, "desarrollan la capacidad relacional, mejoran la conexión escolar, promueven la autorregulación y las habilidades de resolución de conflictos, etc." ${ }^{73}$.

Pese a todo lo anterior, los retos en dicha materia continúan pendientes, todo ello partiendo de la necesaria adaptación de los propios principios de la Justicia Restaurativa a la población menor de edad. De este modo, siguiendo a Bernuz Benitez, indica la autora que son dos los temas relacionados que merecerían especial atención en lo que respecta a la aplicación de los principios de la Justicia Restaurativa a la Justicia de Menores, a saber ${ }^{74}$ :

a. Lo que compete a la inclusión de las víctimas del delito en una jurisdicción que presenta como objeto central la protección e interés superior del menor. En esta línea, no hay que olvidar el papel

70 WALGRAVE, L., "Restorative justice and human rights ... cit., p.137.

71 SMITH, B., "Restorative justice and bullying", in T. Gavrielides (Ed.), Rights and restoration within youth justice, Sitter Publications: Canada, 2012, pp. 469-470.

${ }^{72}$ MORRISON, B., "Schools and restorative justice", in G. Johnstone and D. Van Ness (Eds.), Handbook of restorative justice, Cullompton, UK: Willan Publishing, 2007, p. 325.

${ }^{73}$ GONZÁLEZ, T., ETOW, A. \& DE LA VEGA, C., "Health Equity, School Discipline Reform, and Restorative Justice", The Journal of Law, Medicine and Ethics, 47S2, 2019, p.49. DOI: https://doi.org/10.1177/1073110519857316. Puede ampliarse información para casos específicos en: BAILEY, M.H.A., "Restorative Justice: Moving from Punitive Sanctions to Proactive Interactions", Critical Schooling, 2019, pp. 47 y ss. DOI: https://doi. org/10.1007/978-3-030-00716-4_3

${ }_{74}$ BERNUZ BENEITEZ, M.J., "Las posibilidades de la Justicia Restaurativa ... cit., pp. 14 y ss. 
principal que otorga la Justicia Restaurativa a la víctima implicada en el proceso; ahora bien, ¿contradeciría ello la demanda de una atención especial y prioritaria hacia los menores que marca el Sistema de Justicia? Se hablaría por tanto de dos perspectivas bajo dos modelos garantistas que buscan la máxima protección de las partes del conflicto bajo el prisma de lo "justo", debiendo evitar a toda costa que se instrumentalice la figura de la víctima en beneficio de la misma Justicia de Menores, principalmente en lo que ataña a la aplicación de medidas extrajudiciales.

b. El respeto de los derechos dentro del entorno que marca la Justicia Restaurativa marcado por una mayor flexibilidad que las vías oficiales, que no por ello menos serio. En este sentido, tal y como refiere la autora, el respeto incondicional o sin límites de los derechos fundamentales y garantías procesales no puede desvirtuar el proceso alternativo, pues aun siendo éste de un carácter más distendido e informal, lo cierto es que la legitimidad del proceso debe siempre garantizarse, al igual que ocurriría con otra sería de principios, como serían el de intervención mínimo o el de seguridad jurídica.

En definitiva, si bien la Justicia Restaurativa debiera de ser una de las herramientas de elección prioritaria dentro de la jurisdicción de menores, lo cierto es que su aplicación deberá valorarse atendiendo a las circunstancias que generaron tal conflicto y características de las partes, pues no sería coherente su aplicación "sin proporcionalidad" alguna a ciertos delitos (p.ej., de especial lesividad), así como tampoco debe basarse su instauración en el resarcimiento de todos aquellos aspectos objeto de solvencia en el menor "victimario" (p.ej., patrones de conducta disfuncionales) en detrimento de las garantías de las víctimas.

\section{PROGRAMAS DE JUSTICIA RESTAURATIVA}

\section{Características generales}

La base de la Justicia Restaurativa advierte sobre la necesidad de considerar otro tipo de mecanismos alternativos al proceso, esto es, herramientas que promuevan y favorezcan una participación más activa por parte de los involucrados y cuyo objetivo se base en una solución para ambas. En este sentido, autores como Vanfraechem y Bolívar establecen los siguientes valoras y principios específicos como parte de la praxis en el proceso de Justicia Restaurativa ${ }^{75}$ :

${ }^{75}$ I. VANFRAECHEM \&, D. BOLÍVAR, "Restorative justice and victims of crime...cit., pp.52 y ss. 
a) No dominación/inclusión/colaboración. La Justicia Restaurativa debe favorecen la implicación de la víctima y delincuente en la toma de decisiones, evitando cualquier tipo de dominación de una parte sobre la otra (desequilibrio de poder), de esta forma, se asegura una colaboración de las partes para la resolución del conflicto en el que las posturas de cada una de ellas sean tenidas en cuenta de cara a la solución definitiva.

b) Compensación/restauración/necesidades de las víctimas. La concienciación del delincuente del daño causado contribuye a empatizar con la víctima tanto en las secuelas personales como interpersonales generadas, restaurando así sus sentimientos de respeto, dignidad, sentido de seguridad y control. De esta manera, no solo se pretende restaurar una posible y previa relación entre las partes, o solventar un conflicto entre personas desconocidas con anterioridad al hecho ilícito, sino también entre la víctima y la comunidad como fuente de apoyo.

c) Potenciación/fortalecimiento/autonomía (empowerment). El sentimiento de implicación durante el proceso ayudaría al sentido de autoeficacia percibido por las víctimas durante todo el proceso, manteniéndose como parte del mismo, siendo oídas y tenidas en cuenta en la búsqueda de una solución común a través de su participación activa.

Dentro del ámbito de la Justicia Restaurativa, si bien las medidas alternativas de resolución de conflictos (MARC) —o por sus siglas en inglés $\mathrm{ADR}$, en base al concepto de "alternative dispute resolution"-, podrían tener cabida en distintas esferas del Ordenamiento Jurídico ${ }^{76}$, lo cierto es que sería en el propio ámbito penal donde se extreman las mayores precauciones en su aplicación. Pese a ello, si bien la gestión del conflicto puede abarcar tanto lo judicial como lo extrajudicial, Redorta resume en la siguiente imagen las características de los tipos o modalidades de gestión de conflicto, a saber ${ }^{77}$ :

76 Más información en: CHICO DE LA CÁMARA, P., Las medidas alternativas de resolución de conflictos (ADR) en las distintas esferas del ordenamiento jurídico, Valencia, Tirant lo Blanch, 2018.

77 REDORTA, J., "Entorno de los métodos alternativos de solución de conflictos", Revista de Mediación. Año 2, No 3, 2009, p. 31. 


\section{Imagen 2. Continuo de métodos de gestión de conflictos ${ }^{78}$.}

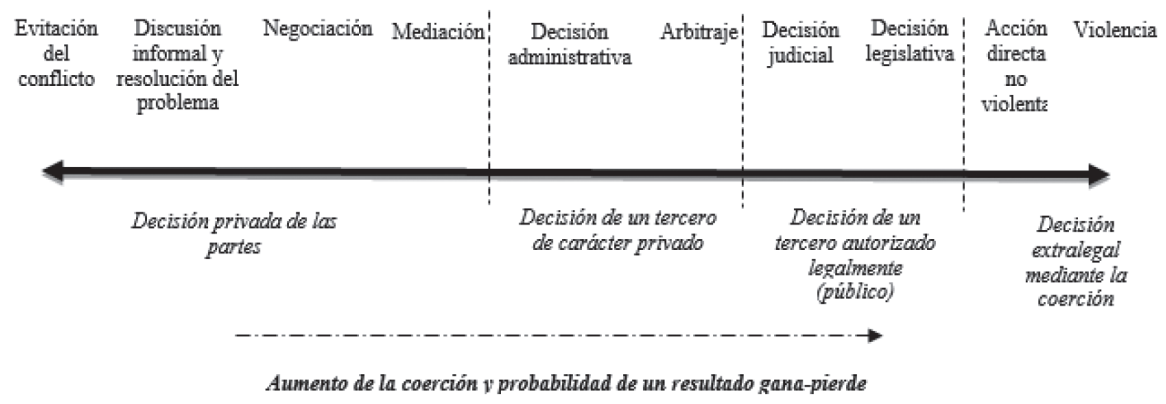

Tal y como puede apreciarse en la imagen anterior, dentro de un continuo de resolución de conflictos entrarían diversas técnicas o mecanismos, siendo los extremos los que competente a la evitación del mismo y a su confrontación (violencia). De esta forma, conforme se avanza de un extremo a otro a lo largo del continuo, concretamente hacia la parte de decisoones extralegales coercitivas, se viene a incrementar la probabilidad "ganacias-pérdidas", llegando de esta forma a una forma más desigualitaria en cuanto al reparto de beneficios y consecuencias. Dicho ello, y tomando en consideración algunas de las opciones de resolución propuestas — precisamente por su relevancia en la práctica-, baste advertir lo siguiente en relación a cada una de ellas:

a) Mediación. Siguiendo la Recomendación del Comité de Ministros del Consejo de Europa, de 15 de septiembre de 1999, y en línea similar a la ya mencionada posterior Recomendación 2018/8, la mediación se propone como instrumento idóneo en la resolución alternativa de conflictos, definiendo de formas específica la mediación penal como un "proceso en el que la víctima y el infractor, si lo aceptan voluntariamente, participan activamente en la resolución de las consecuencias derivadas del delito, mediante la ayuda de una tercera parte imparcial, llamada mediador" 79. En este sentido, se podría entender la mediación de diferentes formas,

78 Ibídem.

79 Recomendación N R (99) 19 del Consejo de Europa sobre Mediación en Justicia Penal. Vid. más información al respecto en: https://search.coe.int. Vid. igualmente la Comunicación de la Comisión al Consejo, al Parlamento Europeo y al Comité Económico y Social sobre las víctimas de delitos en la Unión Europea —normas y medidas (COM(1999) 349 final, 14 de julio de 1999)_, la refiere que la mediación entre víctima y victimario podría ser una alternativa a un procedimiento criminal largo y desalentador, en interés de las víctimas, posibilitando la indemnización del daño o la recuperación de los bienes robados al margen de un procedimiento penal normal. Vid.: https://eur-lex.europa.eu. En la misma línea la reciente Recomendación de 2018. 
bien como valor en cuanto al contacto pacífico del dialogo entre las partes, bien como gestión de conflicto o técnica específica de resolución de problemas dentro de un entorno idóneo y mediante la participación de un tercero parcial y neutral (mediador) ${ }^{80}$. Así pues, lo cierto es que la mediación, como un tipo de proceso voluntario y quizás la más practicado, debe comprenderse bajo el prisma de una de las múltiples herramientas que pone en práctica los principios que caracterizan a la Justicia Restaurativa, pese a no ser exactamente los mismos conceptos.

b) Negociación. Se trata de un sistema autocompositivo (cooperación de las partes) en el que dos o más partes con intereses antagónicos intentan llegar a un acuerdo mediante el cese de algún aspecto; pese a ello, el diálogo sigue siendo la herramienta por excelencia. A diferencia de la mediación, lo normal es que sean las propias partes las que intervienen en exclusividad, aunque lo cierto es que en ciertas situaciones se echa mano de expertos para orientar, no vincular, la resolución ${ }^{81}$.

c) Conciliación. Si bien no mencionada en la imagen anterior, la conciliación se define como otro mecanismo autocompositivo basado en el diálogo, voluntad y decisión de la solución por las propias partes, no por parte de un tercero. En cualquiera de los casos, indica San Cristobal Reales que, llevándose a cabo siempre que la materia sea dispensable, la conciliación puede darse antes del inicio del proceso (preprocesal), teniendo por tanto naturaleza de jurisdicción voluntario, o poner fin al mismo una vez ya iniciado (procesal), teniendo lugar dentro del mismo proceso donde el Juez competente ya conoce el asunto del mismo. Así pues, en caso de no prosperar por la citada vía, será la Administración la encargada de marcar la resolución como tercero imparcial o neutral a través de Sentencia ${ }^{82}$.

d) Arbitraje. En esta ocasión existe la figura de un "árbitro" que toma decisiones vinculantes para las partes. Así pues, a diferencia de los mecanismos anteriores, este proceso se deja en manos de terceras personas a cuyas decisiones se someten las partes. En este caso, al depender las soluciones de una tercera persona distinta a las involucradas, y por tanto no existir diálogo entre las partes, la opción de solución a la que se llega podría ser percibida como más discriminatoria.

80 REDORTA, J., "Entorno de los métodos alternativos... cit., p. 31.

81 SAN CRISTOBAL REALES, S., "Sistemas alternativos de resolución de ocnflictos: negociación, conciliación, arbitraje, en el ámbito civil y mercantil”, Anuario Jurídico y Económico Escurialense, XLVI (2013, pp. 44 y ss.

82 Ibidem, pp.45 y ss. 
Pese a todo lo anterior, la comprensión de los MARC no debe exclusivamente cerrarse a las opciones expuestas con anterioridad, pudiendo hablar de otros recursos que ofrecen resultados muy satisfactorios (p.ej., fact finding, conferencing, diálogo apreciativo, los Ombudsman, etc. ${ }^{83}$. En cualquiera de los casos, sea cual sea la técnica de resolución de conflictos empleada, deberá siempre actuarse con la máxima diligencia.

En base a lo anterior, y siguiendo la Recomendación $\mathrm{N}^{\circ} \mathrm{R}$ (99) 19, de 15 de septiembre de 1999, del Comité de Ministros del Consejo de Europa a los Estados miembros, sobre mediación en materia penal, dicho proceso alternativo gozará de las siguientes características ${ }^{84}$ :

i. Solo podrá llevarse a cabo si las partes consienten libremente.

ii. Todo lo que se dialogue durante el proceso será de carácter confidencial, salvo el acuerdo al que lleguen las partes.

iii. El acceso a la vía de la mediación debe de estar disponible en cuanto a su práctica o ejercicio, siempre que las circunstancias lo permitan.

iv. Los servicios de mediación gozarán de autorresponsabilidad y autonomía.

En el mismo sentido comulga la ya mencionada Recomendación del año 2018, siendo una oportunidad tanto para analizar o examinar la situación de los procesos restaurativos en España, así como en el resto de Europa, como para potenciar programas de actuación más eficaces y acordes con los postulados y principios reparadores, señalando en cualquier caso los beneficios potenciales que dicha práctica comporta ${ }^{85}$.

Ahora bien, unido a lo anterior, evidentemente surgen obstáculos para la resolución de conflictos que son necesarios saldar, pues de otro modo sería imposible llegar a contemplar las características previamente aludidas y, por tanto, dar comienzo a un proceso de mediación. En este sentido, autores como Ríos et al., indican entre las dificultades de las

83 REDORTA, J., "Entorno de los métodos alternativos de solución de conflictos", Revista de Mediación. Año 2. $N^{o}$ 3, 2009, pp.31 y ss.

${ }^{84}$ Recomendación $N^{\circ} \mathrm{R}$ (99) 19 del Consejo de Europa sobre Mediación en Justicia Penal. Vid. más información al respecto en: https://search.coe.int. Vid. igualmente la Comunicación de la Comisión al Consejo, al Parlamento Europeo y al Comité Económico y Social sobre las víctimas de delitos en la Unión Europea —normas y medidas(COM(1999) 349 final, 14 de julio de 1999)—, la refiere que la mediación entre víctima y victimario podría ser una alternativa a un procedimiento criminal largo y desalentador, en interés de las víctimas, posibilitando la indemnización del daño o la recuperación de los bienes robados al margen de un procedimiento penal normal. Vid.: https://eur-lex.europa.eu. En la misma línea la reciente Recomendación de 2018.

85 VARONA, G. y TAMARIT, J.M., "Sección especial: La Recomendación (2018) 8... cit., p. 125. 
partes enfrentadas a la hora de dar comienzo a la búsqueda de una resolución pacífica de soluciones las siguientes, a saber ${ }^{86}$ :

a. Imponer la versión unilateral del conflicto.

b. Identificar a la persona con el acto conflictivo.

c. Valorar en mayor medida las pérdidas en relación con las ganancias.

d. Temer una pérdida de poder.

e. Limitar el diálogo o la comunicación.

f. Emplear la fuerza como la mejor vía de solución.

g. Generar juicios erróneos a partir de falsas percepciones.

Se trata de obstáculos a la búsqueda de alternativas pacíficas o restaurativas al conflicto generado lo que, en cualquier caso, requieren de una modificación si se quiere comenzar con el proceso de mediación. En este sentido, es de vital importancia realizar una previa reflexión individual que permita modificar pensamientos y adaptarlos, tanto a la realidad, como a los intereses comunes para las partes involucradas en el proceso.

\section{Aplicación en el ámbito penal: adecuación y prevención}

Comprendiendo el Derecho Penal a través de su intervención mínima conforme a su actuación en ultima ratio, lo cierto es que, desde una perspectiva preventiva, mecanismos alternativos como la mediación pudieran facilitar la esencia más reinsertadora y rehabilitadora que busca aquella jurisdicción a través del propio Sistema Penitenciario. Ahora bien, lo cierto es que existe cierta desconfianza social respecto a dichas medidas, pues focalizando la actuación en lo que sería la prevención especial sobre el delincuente, podrían entenderse aquéllas como una oportunidad para éste en detrimento de la que fue víctima, así como de futuras víctimas potenciales. En esta línea, y como refiere el Manual de Naciones Unidas del año 2006 previamente mencionado, los "programas de Justicia Restaurativa pueden ser utilizados para reducir la carga del Sistema de Justicia Penal, para desviar casos fuera del mismo y para proporcionarle una gama de sanciones constructivas" 87 , lo que vuelve de nuevo a poner de manifiesto la especial cautela que debe comportar el no desvirtuar la

${ }^{86}$ RÍOS, J., OASCUAL, E., SEgOVIA, J.L., ETXEBARRÍA, X. y LOZANO, F., Mediación penal, penitenciaria y encuentros restaurativos. Experiencias para reducir el sufrimiento en el sistema penal, Madrid, Comillas, 2016, pp. 201 y 202.

87 OFICINA DE LAS NACIONES UNIDAS CONTRA LA DROGA Y EL DELITO (UNODC), Manual sobre programas de Justicia Restaurativa... cit., p. 2. 
esencia de la Justicia Restaurativa para desahogar el ámbito de la jurisdicción penal.

Centrando la cuestión en la mediación penal, lo cierto es que su aplicación no ha estado exenta de críticas, precisamente por su caracterización como forma extrajudicial de solución de conflictos en las que deben de respetarse un conjunto de principios que emanan del Derecho Penal, precisamente porque luego serán los que vengan a considerarse mientras se llega a la solución pactada por las partes como alternativa a aquella vía. De manera específica, siguiendo a autoras como Cervelló Donderis, debe tenerse en cuenta que los nuevos postulados de la Justicia Restaurativa advierten de un tipo de intervención en la que ${ }^{88}$ :

a) El hecho ilícito o delito se comprende como un conflicto social donde existen intereses contrapuestos y/o distintos para las partes, todo ello bajo el prisma de un sistema de actuación dinámico y de intercambio de visiones y alternativas entre las partes. Así pues, como la misma indica, el delito ya no se comprendería, propiamente, como una infracción penal.

b) La responsabilidad se aborda a partir de un conjunto de circunstancias desencadenantes (p.ej., consideración del entorno social), no tanto como juicio individual.

c) Los protagonistas son víctima y victimario.

d) El control no lo tiene el poder judicial, el Estado, sino la propia comunidad, la cual también tendrá un papel esencial en la reintegración o reinserción social del delincuente.

e) El objeto se centra en la resolución del conflicto de la manera más adecuada para ambas partes, en asunción de la responsabilidad por el hecho cometido y en su reparación, y no tanto en la sanción del delito.

En lo que atañe de manera específica a los programas de actuación, autores como Carnevali Rodríguez destacan el compromiso de los programas de Justicia Restaurativa dentro del ámbito de la Justicia Juvenil. De manera específica, describe cómo determinados programas llevados a cabo en Nueva Zelanda con las conocidas "Conferencias Familiares" (Family Group Conferences), vienen a ser bastante exitosas en este ámbito ${ }^{89}$. Así, tratándose de un programa de actuación en el que intervienen infractor, víctima, familiares, y opcionalmente abogado, policía, y otros

88 CEVELLÓ DONDERIS, V., "Los principios penales como criterio regular de la selección de delitos mediables", en V. Domingo (Coord.) et al., Una mirada hacia la Justicia Restaurativa: Recuperando el derecho perdido, Criminología y Justicia No4, 2012, pp. 35-44.

${ }_{89}$ CARNEVALI RODRÍGUEZ, R., "La justicia restaurativa como mecanismo de solución de conflictos. Su examen desde el derecho penal", Justicia Juris, 13 (1), 2017, p.130. 
profesionales relevantes, dicho programa tiene como objetivo prioritario no la reparación, sino la asunción de la responsabilidad por parte del victimario. En este sentido, si bien se han apreciado efectos positivos de cara a la prevención de la reincidencia delictiva, lo cierto es que sería importante señalar que no tanto lo prioritario es la asunción de la responsabilidad en cuanto a la probabilidad de no reincidencia futura, sino los procesos de reestructuración cognitiva que se efectúen en la intervención con el sujeto, de manera que la modificación de conducta posterior se apoyará en un sólido y afianzado proceso de cambio en los esquemas mentales.

Centrando la cuestión en lo que compete a la evitación de la reincidencia delictiva en internos, y dejando el margen las distintas fases en que la mediación se hace presente dentro del proceso penal (mediación penal en la fase de instrucción, mediación penal en la fase de enjuiciamiento, y mediación penal en la fase de ejecución de la sentencia penal), lo cierto es que una de las vertientes más atractivas en cuanto a la aplicación de la mediación atañe precisamente a la que se lleva a cabo en los centros penitenciarios entre víctima y persona penada. En este sentido, una vez exista el consentimiento voluntario del penado para dar inicio al proceso de mediación, será el propio Centro Penitenciario el que contacto con el Servicio de Medicación dando a conocer dicho extremo de cara a comenzar el proceso de mediación. Igualmente, y a expensas de que la víctima también muestre su interés en participar, serán los propios servicios del Juzgado de Vigilancia Penitenciaria, concretamente el Equipo mediador, el que lleve el proceso, siendo el encargado de ir remitiendo la información pertinente, relativa al desarrollo de la mediación, tanto al Director del Centro penitenciario en cuestión como al Juzgado de Vigilancia Penitenciaria.

Pese a lo anterior, también cabría destacar la propia mediación que se emplea en la resolución de conflictos entre los propios internos ("mediación penitenciaria”). En esta línea, el desarrollo de un conflicto interpersonal entre penados no es algo inusual, pues precisamente su frecuencia podría venir establecida por las propias características del entorno en el que se encuentran, así como de la frustración generada por el motivo del ingreso; todo lo cual genera un caldo de cultivo evidente para las disputas dentro de la Institución Penitenciaria, más aún si se tiene en cuenta el distanciamiento familiar que diariamente vive el interno. Así pues, si bien es cierto que existen un conjunto de mecanismos institucionales y legales propios del ámbito penitenciario que permiten actuar ante la existencia de ciertas problemáticas específicas (p.ej., aplicación del régimen disciplinario), lo cierto es que la mediación, dentro de un contexto en el que la convivencia con el resto de internos va a ser obligada, o donde el espacio para la intimidad se ve prácticamente muy reducido — si es que hay alguno-, las medidas alternativas de resolución de conflicto suponen una de las mejores soluciones precisamente, para fomentar la autorresponsabilidad, autocontrol y, sobre todo, la necesidad 
de saber que ante un conflicto no siempre hay una persona que pierde, sino que ambas partes pueden obtener beneficios.

Finalmente, y desde una perspectiva preventiva que pudiera justificar un mayor uso de la Justicia Restaurativa, autores como Carnevali Rodríguez apuntan a la disminución de los procesos de victimización secundarios como resultado de estos mecanismos alternativos, principalmente sustentado en la ausencia de la revivencia o reexperimentación del hecho traumático que le supondría el propio proceso penal. Concretamente, al estar apoyados en una dinámica que huye de la confrontación entre las partes, fomenta el diálogo, y evita que la víctima se pueda sentir intimidada, la tarea de conseguir un acuerdo de la manera más satisfactoria, y gratificante para las partes, se hace más sencilla ${ }^{90}$.

\section{CONCLUSIONES}

Como se ha puesto de manifiesto a lo largo del texto, el reconocimiento de la Justicia Restaurativa pone de manifiesto la existencia de la rama más humanitaria del Derecho Penal, dejando al margen la ya muy cuestionada y practicada privatización de la Justicia. En este sentido, las medidas alternativas de resolución de conflictos se abren paso en una sociedad que, si bien dividida entre quienes abogan por un mayor endurecimiento punitivo y quienes defienden una mayor laxitud del sistema, no viene sino siendo eco de las recomendaciones internacionales en la citada materia.

Los beneficios que comporta la aplicación de vías extrajudiciales son múltiples, no solo por agilizar el propio quehacer de la Administración, sino por incidir principalmente en un tipo de prevención especial positiva en el infractor que defiende una reparación y compensación por el daño causado frente a la limitación de la libertad. Ahora bien, tal y como se ha cuestionado, lo cierto es que la protagonista de cualquier proceso restaurativo es la víctima, no debiendo bajo ningún concepto desvirtuar el proceso a su costa. Así pues, si bien es cierto que la evitación de la reincidencia futura es un punto esencial objeto de la Justicia Restaurativa, también es verdad que tal finalidad no se realizará si previamente no se asegura la inexistencia de riesgo de revictimización alguno. Igualmente, el fenómeno delictivo abarca más que las partes directamente implicadas, estableciéndose la propia comunidad como un agente más a considerar en la toma de decisiones que se lleven a término a través de los procedimientos alternativos a las vías oficiales.

90 CARNEVALI RODRÍGUEZ, R., “La Justicia Restaurativa como mecanismo de solución de conflictos. Su examen desde el derecho penal”, Justicia Juris, 13 (1), 2017, p. 131. 
Tal y como se ha mencionado previamente, los menores constituyen un colectivo de especial vulnerabilidad, siendo precisamente en los casos en que los menores son infractores aquellos en los que la reflexión sobre la aplicabilidad de la Justicia Restaurativa debiera de estar más presente. Así, por ejemplo, una buena solución ya mencionada con anterioridad sería su práctica para la resolución de conflictos en los primeros años de escolarización, lo que vendría a solucionar los problemas de una forma mucho más disciplinada al tiempo que ayudaría a manejar ciertas carencias presentes en los menores de edad mediante la enseñanza de las habilidades y destrezas necesarias (p.ej., tolerancia a la frustración, niveles de impulsividad, gratificación inmediata). Con ello precisamente lo que se tarta es de advertir sobre la importancia de instaurar unos hábitos y formas de relacionarse adecuadas durante las primeras etapas del desarrollo, de forma que dichos patrones de conducta se asienten correctamente en los menores de edad y sean capaces de "prevenir" un comportamiento disfuncional y antisocial en etapas posteriores.

En definitiva, si bien en cierto que la aplicación de las medidas alternativas propias de las corrientes restaurativas viene a ser todavía escasa en su práctica - al contrario de lo que sucede en el ámbito civil y mercantil-, lo que sí que es verdad es que cada vez existe un mayor reclamo hacia su empleo. Pese a ello, todavía queda un largo camino por recorrer en cuanto a los tipos de ilícitos penales en lo que sí podría tener cabida la aplicación de tales medidas y los beneficios que ello comportaría.

\section{BIBLIOGRAFÍA}

ARANDA JuRADO, M., "La promoción de la Justicia Restaurativa en materia penal por Naciones Unidas a través de sus Congresos Internacionales”, Revista Boliviana de Derecho 27, 2019.

Artinopoulou, V., "Restorative justice and Psychology: positivism in Criminology again?", in T. Gavrielides (Ed.), The Psychology of restorative justice: Managing the power within, Ashgate, Surrey (England), 2015.

BaILey, M.H.A., "Restorative Justice: Moving from Punitive Sanctions to Proactive Interactions", Critical Schooling, 2019, 47-74. DOI: https:// doi.org/10.1007/978-3-030-00716-4_3

Beloff, M., Kierszenbaum, M. y Terragni, M., "La justicia juvenil y el juicio por jurados", Revista de Derecho Penal y Criminología, Núm. 10, 2017, 153-168.

Bernuz Beneitez, M.J., "Las posibilidades de la Justicia Restaurativa en la Justicia de Menores (española)", Revista Electrónica de Ciencia Penal y Criminología (RECPC), 16-14, 2014, 1-27.

Blanco, R., Díaz, A., Heskia, J y Rojas, H., Justicia Restaurativa: Marco Teórico, Experiencias Comparadas y Propuestas de Política Pública, 
Universidad Alberto Hurtado, Colecciones de Investigaciones Jurídicas 6, 2014.

Braithwaite, J., Crime, shame and reintegration, Cambridge: Cambridge University Press, 1989.

BRAIthwaIte, J., Restorative justice and responsive regulation, New York: Oxford University Press, 2002.

CARneVAli Rodríguez, R., "La justicia restaurativa como mecanismo de solución de conflictos. Su examen desde el derecho penal", Justicia Juris 13 (1), 2017, 122 - 132.

CeVelló Donderis, V., "Los principios penales como criterio regular de la selección de delitos mediables", en V. Domingo (Coord.) et al., Una mirada hacia la Justicia Restaurativa: Recuperando el derecho perdido, Criminología y Justicia $\mathrm{N}^{\mathrm{o}} 4,2012$.

CHICO DE LA CÁMARA, P., Las medidas alternativas de resolución de conflictos (ADR) en las distintas esferas del ordenamiento jurídico, Valencia, Tirant lo Blanch, 2018.

CHOy Á Fores, N., "Prácticas restaurativas: círculos y conferencias", Justicia restaurativa: nuevas perspectivas en mediación, 2014-2015, pp. 9 y ss. Vid.: http://www.pensamientopenal.com.ar/system/files/2015/07/ doctrina41593.p

COMISIÓN EuRopeA, Inteligencia artificial para Europa, Comunicación de la Comisión al Parlamento Europeo, al Consejo, al Comité Económico y Social Europeo y al Comité de las Regiones, Bruselas, 25.4.2018 COM (2018) 237 final [SWD(2018)137final 1\}.

Consejo Económico y Social de Naciones Unidas, 2002/12 Principios básicos para la aplicación de programas de justicia restitutiva en materia penal, Naciones Unidas, 7 de enero de 2002.

Consejo Económico Y Social De Naciones Unidas, 2016/17, recomendación de la Comisión de Prevención del Delito y Justicia Penal (E/2016/30), Naciones Unidas.

COUNCIL OF EUROPE, Guidelines to respect, protect and fulfil the rights of the child in the digital environment, Building a Europe for and with children, Recommendation CM/Rec(2018)7 of the Committee of Ministers 2018.

DoERnER, W.G. \& Lab, S.P., Victimology ( $5^{\text {th }}$ Ed.), Cincinnati, OH: LexisNexis, 2008.

DOMINGO DE LA FUENTE, V., "Contexto teórico-práctico de la justicia restaurativa en Europa con especial atención a España”, en V. Domingo (Coord.) et al., Una mirada hacia la Justicia Restaurativa: Recuperando el derecho perdido, Criminología y Justicia Nº4, 2012. 
FERNÁNDEZ BERMEJO, D., "El fin constitucional de la reeducación y reinserción social ¿un derecho fundamental o una orientación política hacia el legislador español?", ADPCP, Vol. LXVII, 2014, 1-53.

FLETcher, G., Gramática del derecho penal (Trad. MUÑOZ CONDE, F.), Buenos Aires: Hammurabi, 2008.

GaL, T., Child victims and restorative justice, Oxford: Oxford University Press, 2011.

Garland, T. \& Policastro, C., "Victimization of the vulnerable", in T.N. Richards and C.D. Marcus, Sexual victimization: Then and now, London, SAGE publications, 2015.

GAVRIELIDES, T., "Bridging restorative justice and human rights for youth justice", in T. Gavrielides (Ed.), Rights and restoration within youth justice, Sitter Publications: Canada, 2012.

González, T., Etow, A. \& De La Vega, C., "Health Equity, School Discipline Reform, and Restorative Justice", The Journal of Law, Medicine and Ethics, 47S2, 2019, 47-50. DOI: https://doi. org/10.1177/1073110519857316

JERICó OJER, L., "El impacto (probablemente no previsto) de la reforma del Código Penal operada por la LO 1/2015, de 30 de marzo, en el Derecho Penal de Menores", Revista Electrónica de Ciencia Penal y Criminología (RECPC), 20-24, 2018, 1-56.

Johnstone, G. \& VAn Ness, D., "The meaning of restorative justice”, in G. Johnstone and D. Van Ness (Eds.), Handbook of restorative justice, Collumpton, Willan Publishing, 2007.

LAUWAER, K., "European criminal justice policies on victims and restorative justice", in I. Vanfraechem, D. Bolívar and I. Aertsen (Eds.), Victims and restorative justice, Oxfordshire, Routledge, 2015.

Marshall, T., Restorative justice: an overview, technical report. London: Home Office, 1999.

Mc Cold, P., Paradigm muddle: The threat to restorative justice posed by its merger with community justice, Contemporary Justice Review 7(1), 2004, 13-35.

Mc Cold, P., "La reciente justifica restaurativa. Mediación, círculos y conferencias", Delito y Sociedad 35 (22), $2^{\circ}$ semestre 2013, pp.9-44.

Miers, D., An International Review of Restorative Justice. Crime Reduction Research Series Paper 10, Barry Webb Home Office Policing and Reducing Crime Unit, London, 2001.

MontolLi, C.A. \& DA CRUZ, M.A., "Justiça restaurativa e maioridade penal: efectivação do Estatuto da Criança e do Adolescente e Justiça Humanizada", Revista de Derecho Penal y Criminología, Núm. 10, 2017, 140-152. 
Morillas Fernández, D.L., Patró Hernández, R.M. y Aguilar Cárceles, M.M., Victimología: Un estudio de la víctima y los procesos de victimización, Madrid, Dykinson, 2014.

Morris, A. \& MAXWELL, G., "Implementing restorative justice: What Works?”, in J. Hudson, A. Morris, G. Maxwell, and B. Galaway (Eds.), Restorative justice for juveniles: conferencing, mediation and circles, Portland, OR: Hart Publishing, 2001.

Morrison, B., "Schools and restorative justice", in G. Johnstone and D. Van Ness (Eds.), Handbook of restorative justice, Cullompton, UK: Willan Publishing, 2007, p.325.

Naciones Unidas (Naciones Unidas), Congresos de las Naciones Unidas sobre prevención del delito y justicia penal 1955 - 2015. 60 años de logros, United Nations Information Service, 2015.

Oficina de las Naciones Unidas contra la Droga y el Delito (UNODC), Manual sobre programas de Justicia Restaurativa. Serie de Manuales sobre Justicia Penal, Viena, 2014.

Oficina de las Naciones Unidas contra la Droga y el Delito (UNODC), Manual sobre programas de Justicia Restaurativa. Serie de Manuales sobre Justicia Penal, Viena, 2010.

Oficina de las Naciones Unidas contra la Droga y El Delito (UNODC), Manual sobre programas de Justicia Restaurativa. Serie de Manuales sobre Justicia Penal, Viena, 2006.

PEACHEY, D., “The Kitchener experiment”, en M. Wright and B. Galaway (Eds.), Mediation and Criminal Justice; victims, offenders and community, London, Sage, 1989.

REDORTA, J., “Entorno de los métodos alternativos de solución de conflictos", Revista de Mediación. Año 2. $N^{o}$ 3, 2009, 28-37.

Ríos, J., Oascual, E., Segovia, J.L., Etxebarría, X. y Lozano, F., Mediación penal, penitenciaria y encuentros restaurativos. Experiencias para reducir el sufrimiento en el sistema penal, Madrid, Comillas, 2016.

SAN CRistobal Reales, S., "Sistemas alternativos de resolución de ocnflictos: negociación, conciliación, arbitraje, en el ámbito civil y mercantil”, Anuario Jurídico y Económico Escurialense, XLVI (2013, 39-62.

Smith, B., "Restorative justice and bullying”, in T. Gavrielides (Ed.), Rights and restoration within youth justice, Sitter Publications: Canada, 2012.

TAmarit Sumalla, J.M., "El necesario impulso de la Justicia restaurativa tras la Directiva europea de 2012", Ars Iuris Salmanticensis, Vol. 1, 2013, 139-160. 
Tiana Ferrer, A., "Declaración de los Derechos del Niño y Convención sobre los Derechos del Niño", Transatlántica de Educación, Vol. V, 2008, 95-112.

TYLER, T.R., Why people obey the law, New Haven, CT: Yale University Press, 1990.

Van Ness, D. and Strong, K.H., Restoring justice, Concinnati, OH, Anderson Publishing Co, 1977.

VANFraechem, I. \&, D. Bolívar, "Restorative justice and victims of crime", in I. Vanfraechem, D. Bolívar and I. Aertsen (Eds.), Victims and restorative justice, Oxfordshire, Routledge, 2015.

VARONa, G. y TAMARIT, J.M., "Sección especial: La Recomendación (2018) 8 del Consejo de Europa sobre justicia restaurativa en asuntos penales. El caso de Francia, Italia, Alemania, Suiza y España, Revista de Victimología 8, 2018, 125-184.

WaLgRAVE, L., "Restorative justice and human rights", in T. Gavrielides (Ed.), Rights and restoration within youth justice, Sitter Publications: Canada, 2012.

ZEHR, H., Changing lenses: a new focus for criminal justice, Scottsdale, PA: Herald Press, 1990. 